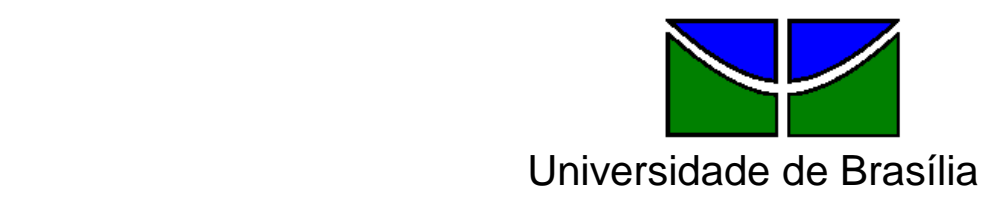

Faculdade de Economia, Administração, Contabilidade e Ciências da Informação e Documentação Departamento de Administração

GABRIELA SAID DE LAVOR

\title{
AVALIAÇÃO DA CAMPANHA PUBLICITÁRIA "VIAJA MAIS MELHOR IDADE” ELABORADA PELO MINISTÉRIO DO TURISMO
}

Brasília - DF

2010 


\section{GABRIELA SAID DE LAVOR}

\section{AVALIAÇÃO DA CAMPANHA PUBLICITÁRIA "VIAJA MAIS MELHOR IDADE”' ELABORADA PELO MINISTÉRIO DO TURISMO}

Monografia apresentada ao

Departamento de Administração como requisito parcial à obtenção do título de Bacharel em Administração.

Professor Orientador: Pedro Henrique Melo Albuquerque

Brasília - DF 
Lavor, Gabriela Said de.

Avaliação da Campanha Publicitária "Viaja Mais Melhor Idade" elaborada pelo Ministério do Turismo / Gabriela Said de Lavor. Brasília, 2010.

$57 \mathrm{f}$. : il.

Monografia (bacharelado) - Universidade de Brasília, Departamento de Administração, 2010.

Orientador: Prof. Pedro Henrique Melo Albuquerque, Departamento de Administração.

1. Políticas Públicas. 2. Avaliação de Programas. 3.Marketing. 4. Propensity Score Matching. I. Título. 


\section{AVALIAÇÃO DA CAMPANHA PUBLICITÁRIA "VIAJA MAIS MELHOR IDADE” ELABORADA PELO MINISTÉRIO DO TURISMO}

A Comissão Examinadora, abaixo identificada, aprova o Trabalho de Conclusão do Curso de Administração da Universidade de Brasília da aluna

\section{Gabriela Said de Lavor}

Prof. Ms. Pedro Henrique Melo Albuquerque

Professor-Orientador

Prof. Dr. Rafael Barreiros Porto

Professor-Examinador
Profa. Dra. Solange Alfinito

Professora-Examinadora

Brasília, 01 de Setembro de 2010. 
Ao Seu Tabajara e Dona Lídia, meus pais, fontes inesgotáveis de inspiração e amor. 
Agradeço a Deus pela minha vida e pela oportunidade de estudar;

Aos meus pais, por caminharem e dividirem comigo cada passo dessa etapa;

Aos meus irmãos, André, Lucas, Licia e especialmente a Cecília, pelo interesse e disponibilidade em ajudar;

Aos meus amigos, por estarem presentes em todos os momentos importantes da minha vida. 


\section{RESUMO}

A política brasileira tem dado ao turismo relevância significativa dentro do leque de atividades econômicas a serem exploradas no país. Políticas públicas vêm sendo formuladas de forma a aumentar a atividade turística nacional. No entanto, a avaliação quantitativa da eficiência dessas políticas ainda é incipiente. Uma das ações estratégias das políticas públicas para o turismo é a criação de campanhas publicitárias. Este estudo tem como objetivo avaliar o impacto da campanha "Viaja Mais Melhor Idade", elaborada pelo Ministério do Turismo em 2007, em termos de aumento do número de hospedagens cadastradas no Ministério. A campanha foi elaborada com o intuito de movimentar o turismo nas épocas de baixa temporada, além de promover a inlcusão social de idosos. Para tal avaliação, foi utilizado o método Propensity Score, que corrige o viés causado pela falta de randomização da amostra. A baixa quantidade de dados coletados pelo órgão é um fator limitador para a elaboração de avaliações precisas. Os resultados obtidos apontam uma diferença não significativa de valor médio entre os meios de hospedagem cadastrados no Ministério do Turismo das Unidades Federativas contempladas na campanha e as que não foram alvo da publicidade em questão. Esse resultado pode ser consequência da pequena quantidade de observações - dada a limitação de dados - ou da real ineficiência da campanha elaborada pelo órgão.

Palavras-chave: Políticas Públicas. Avaliação de Programas. Marketing. Propensity Score Matching. 


\section{SUMÁRIO}

1 INTRODUÇÃO

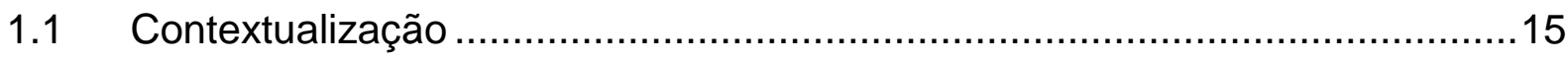

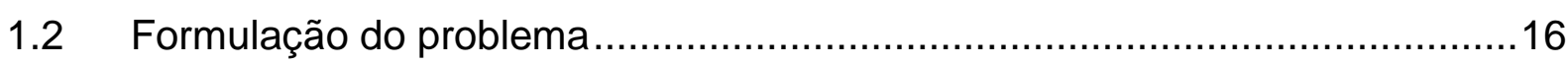

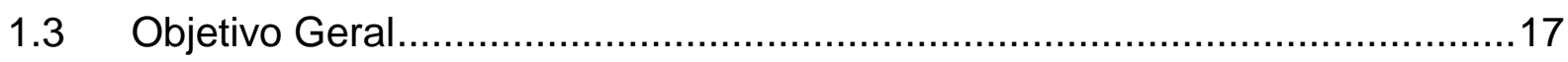

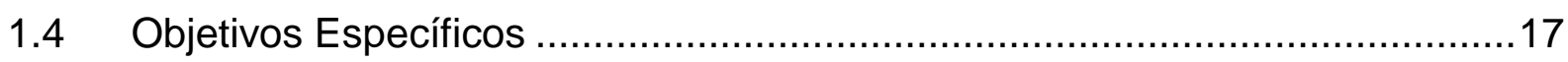

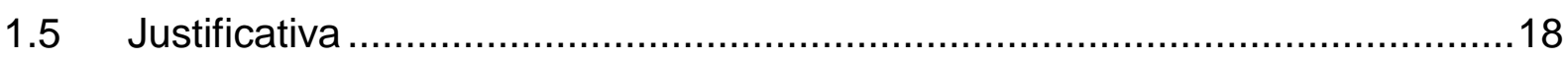

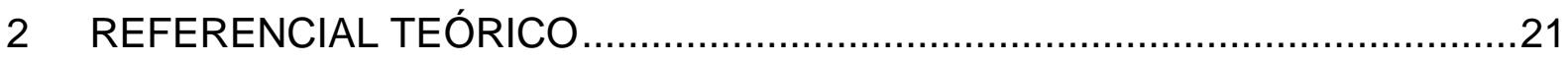

$2.1 \quad$ Turismo

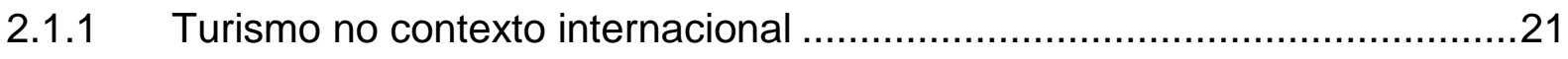

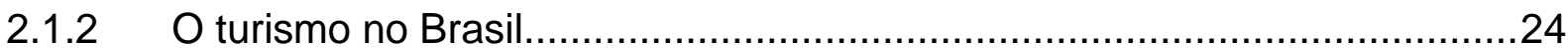

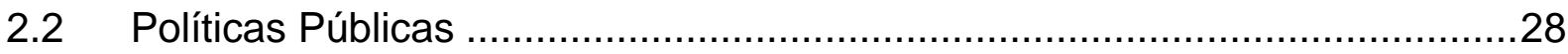

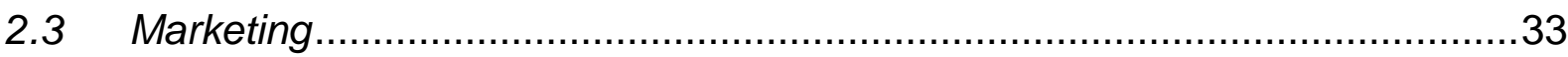

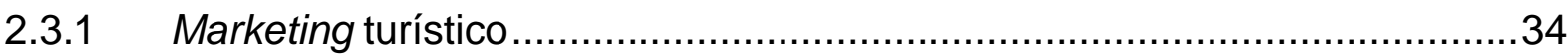

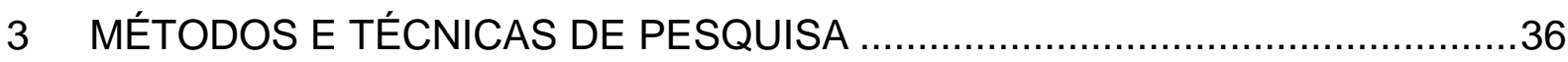

3.1 Tipo e descrição geral da pesquisa .........................................................36

3.2 Caracterização do objeto de estudo ………….......................................38

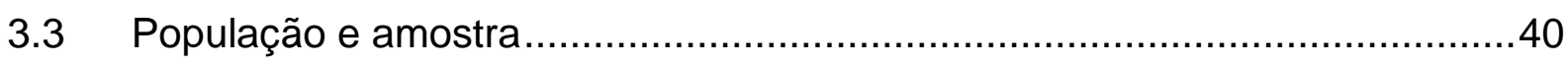

3.4 Procedimentos de coleta e de análise de dados ..........................................41

3.5 Experimentação utilizando Propensity Score Matching .................................43

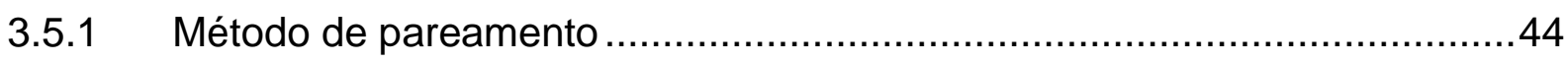

3.5.2 Nearest-Neighbor Marching (pareamento pelo vizinho mais próximo).........46

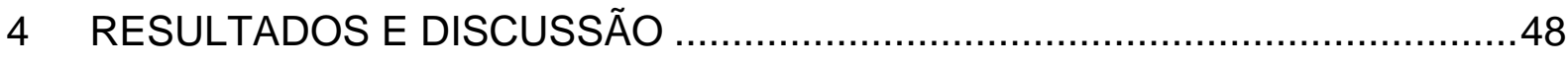

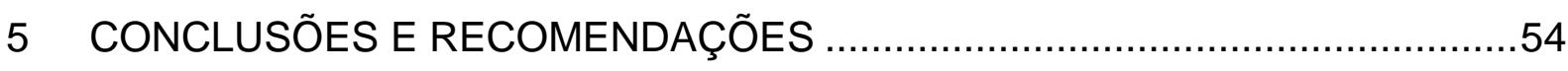

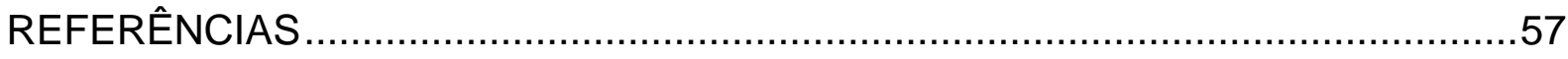

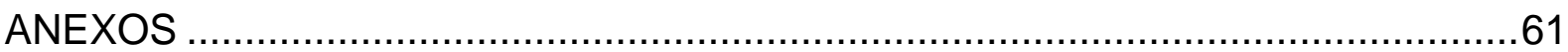


Anexo A - Imagens da campanha "Viaja Mais Melhor Idade" para divulgação no ano

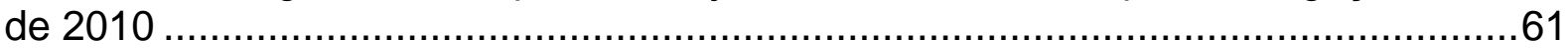

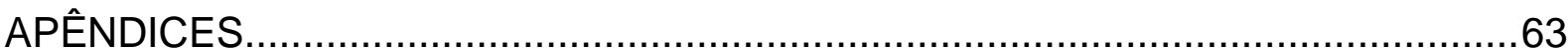

Apêndice A - Variáveis independentes por Unidade da Federação ...........................63 


\section{INTRODUÇÃO}

Em Tomikawa (2009), o turismo é relatado como uma atividade socioeconômica que tem se destacado como um dos fenômenos mais significativos da atualidade. Foi altamente favorecida pelos avanços tecnológicos relacionados aos setores de transporte e comunicação e por acompanhar o processo de globalização vivido pelo mundo a partir do final do século XX e início do século XXI. Esse processo facilitou a circulação de pessoas pelo globo, descomplicando o deslocamento de um país para outro e aumentando o fluxo turístico. Esse cenário é extremamente positivo para a geração de trabalho e renda, em função da potencial capacidade de criação de emprego e ocupações da atividade. De acordo com dados econômicos internacionais, as chegadas internacionais de 2006 foram da ordem de 842 milhões de turistas, o que representa um crescimento médio anual de $6 \%$ desde 1950, ano no qual foi registrado um total de 25 milhões de chegadas internacionais. Nos últimos anos, o fluxo internacional de turistas no mundo registrou um crescimento de $5,2 \%$ de 2004 para 2005 e de $4,5 \%$ de 2005 para 2006. (BRASIL, 2007)

Acompanhando o movimento turístico mundial e aproveitando o potencial brasileiro para essa atividade econômica, foi instituído em 2003 pelo Governo Federal o Ministério do Turismo - MTur. Ao incentivar o desenvolvimento do turismo no País, o governo considera os seguintes fatores: o turismo é um multiplicador do crescimento, sempre acima dos índices médios de crescimento econômico; é intensivo em mão-de-obra, com impactos positivos na redução da violência do país, além de ser uma porta de entrada no mercado de trabalho para os jovens com diferentes níveis de qualificação. Os objetivos principais da instituição do Ministério do Turismo, definida no planejamento estratégico do governo, são a criação de emprego e ocupação, a geração e distribuição de renda, a redução das desigualdades sociais e regionais, a promoção da igualdade de oportunidades, o respeito ao meio ambiente, a proteção ao patrimônio histórico e cultural e a geração de divisas, bem como a inclusão efetiva do Brasil no cenário turístico mundial.

Entre as ações desenvolvidas pelo MTur para fomentar a atividade turística no Brasil está o Plano Nacional. O Plano Nacional de Turismo - PNT 2007/2010: uma viagem de inclusão é o instrumento de planejamento e gestão estratégica das 
ações governamentais no setor e estabelece as diretrizes da Política Nacional de Turismo, que tem como proposta um processo de gestão compartilhada, participativa e descentralizada para promover o desenvolvimento do turismo em todo o País, integrando as diversas instâncias públicas, privadas e do terceiro setor.

Contemplado nesse plano está o Programa de Promoção Nacional do Turismo Brasileiro, que utiliza como referência o Plano de Marketing Turístico Nacional - Plano Cores do Brasil. Esse programa tem como objetivo reunir ações de propaganda, publicidade e participação em eventos que valorizam e divulgam a imagem do destino turístico ao público, fazendo que o mercado brasileiro considereo um produto a ser aproveitado. O Programa tem também ações que visam aumentar os fluxos turísticos domésticos, por meio da formulação e do apoio a campanhas que motivem o turista brasileiro a viajar pelo Brasil, trazendo retorno para o desenvolvimento do seu próprio país.

Essas campanhas publicitárias desenvolvidas pelo Ministério do Turismo têm o apelo de fazer com que o turista brasileiro viaje mais pelo Brasil, consumindo produtos e serviços turísticos e deixando no próprio país a renda gerada com esse consumo. São, assim, responsáveis por fazer crescer a indústria turística, gerando emprego e renda para a população.

Dessa forma, faz-se necessário medir o grau efetivo de contribuição dessas campanhas publicitárias para o aumento da atividade turística no Brasil. Sendo elas - as campanhas - desmembramentos de políticas públicas do governo, que utilizam recursos públicos para serem realizadas, é importante o desenvolvimento de ferramentas de avaliação capazes de medir qual o seu efeito real dentro do objetivo proposto.

Para que essa avaliação seja a mais precisa possível, é necessária a comparação entre grupos que tenham sido atingidos pela política e grupos de controle, ou seja, aqueles que não foram alvo da política pública. A proposta é verificar o impacto efetivo da política traçando relações de causa e efeito excluindo ao máximo outros aspectos que possam ter contribuído para a mudança da realidade estudada, que não as ações governamentais.

Assim, será objeto desse estudo a campanha publicitária "Viaja Mais Melhor Idade", criada pelo Ministério do Turismo em 2007 para estimular viagens domésticas em períodos de baixa ocupação e facilitar o acesso ao turismo por pessoas com idade avançada, promovendo a inclusão social de idosos, 
aposentados e pensionistas. O sucesso da campanha em termos de número de pacotes comprados gera o interesse em que seja calculado o retorno real para o crescimento do turismo no Brasil e a conseqüente geração de renda para as localidades afetadas. As conclusões geradas a partir da análise dos dados podem contribuir com a formulação de estratégias para a implementação das políticas públicas, orientar para que seja mais efetiva a alocação de recursos públicos, além de facilitar a avaliação de como essa alocação vem sendo realizada no caso específico do Ministério do Turismo, além de orientar uma gestão de Marketing publicitário mais efetiva, fornecendo informações úteis para a tomada de decisão.

\subsection{Contextualização}

Um dos setores mais beneficiados com a estabilização da economia a partir de meados dos anos 90 foi o do turismo. A população nacional adquiriu novos hábitos, um deles o da viagem. Neste contexto, o investimento por parte dos órgãos oficiais de turismo em marketing se tornou uma das ferramentas estratégicas mais importantes para o crescimento de um destino turístico (SANTANA, 2006).

Dessa forma, os programas de marketing de destinos "vendem" um produto único, que possui tanto uma experiência única como também uma vasta gama de atributos como belezas naturais, clima, localização geográfica, qualidade das facilidades e serviços, hospitalidade, segurança, história, entre outros. Slogans, eventos, símbolos e campanhas publicitárias são produzidos pelos órgão oficiais de turismo especialmente para diferenciar os seus destinos no mercado global e aumentar a atividade turística do país.

Como grande parte dessas campanhas é elaborada a partir da utilização de recursos públicos, faz-se necessária a avaliação dos efeitos dessas campanhas e investimentos. Em termos de administração, é conhecida a importância da avaliação para qualquer tipo de planejamento. Dentro dos quatro desmembramentos do processo administrativo, a função de Controle engloba o processo de avaliação (CHIAVENATO, 2004). Sem a avaliação, o ciclo de controle fica incompleto, pois não se pode tomar decisões corretivas e modificar um planejamento sem que seja avaliado o desempenho do programa, de acordo com seus objetivos. 
Assim, sendo o turismo um setor com crescente importância para a economia, cada vez mais será atrativo e demandará investimentos. Cabe, então, à Administração Pública, avaliar como são utilizados os recursos destinados à promoção do setor de forma a possibilitar a flexibilização do planejamento para o turismo, direcionando recursos às atividades que trazem o retorno desejado.

\subsection{Formulação do problema}

O planejamento estratégico do Governo Federal tem colocado o turismo como uma de suas prioridades. Acompanhando o movimento mundial de crescimento da relevância dessa atividade econômica, o Brasil tem dado especial importância ao planejamento das atividades do setor, fato comprovado pela instituição, em 2003, de um ministério voltado exclusivamente para estruturação da atividade turística no país (BRASIL, 2007).

Conforme evidencia o PNT 2007-2010 (2007), o planejamento do turismo no Brasil tem sido realizado com base em uma gestão descentralizada, executada com o apoio do Conselho Nacional e de Fóruns Estaduais. O Plano citado comemora os resultados positivos do turismo, chamando a atenção para um aumento significativo no número de desembarques de passageiros de vôos domésticos e internacionais, no número de viagens domésticas realizadas, entre outros.

A comemoração é valida. No entanto, cabe o questionamento de qual é a origem desses resultados positivos. Tais como são medidos hoje, os resultados do turismo não podem ser considerados fruto da boa execução das políticas elaboradas pelo Ministério. Uma série de outros fatores podem ter contribuído para que o número de viagens domésticas realizadas em um determinado período tenha sido maior que o número de viagens realizadas em igual período do ano anterior, o que não deve, necessariamente, ser considerado um sucesso de planejamento e execução do turismo nacional.

Entre as ações formalizadas pelo MTur para a execução de programas voltados ao turismo está a elaboração de campanhas de marketing voltadas para diversos fins, entre eles o estímulo a viagens em feriados prolongados, aumento no número de turistas internacionais por meio da promoção da Marca Brasil, entre 
outras. A campanha "Viaja Mais Melhor Idade" foi elaborada pelo Ministério tendo como público-alvo pessoas com idade acima de 60 anos. A proposta é estimular o aumento no número de viagens domésticas em períodos de baixa temporada, aproveitando a sazonalidade típica do país.

Com base no exposto, o presente estudo pretende responder:

Qual é o retorno real em termos de cadastramento de meios de hospedagem da campanha publicitária "Viaja Mais Melhor Idade" para o turismo no Brasil?

A resposta para essa pergunta poderá orientar o órgão na utilização dos recursos públicos, focando suas atenções e esforços nas campanhas que realmente trazem resultado comprovado para o incremento do turismo no Brasil, além favorecer a eficiência da gestão de marketing no Ministério, alocando os recursos de forma certeira e, em caso de constatação da não efetividade da campanha, investir em outras estratégias publicitárias que possam trazer melhores resultados para 0 setor.

\subsection{Objetivo Geral}

Analisar a efetividade da campanha "Viaja Mais Melhor Idade", lançada em 2007 pelo Ministério do Turismo em termos de aumento na quantidade de meios de hospedagem cadastrados no Ministério do Turismo, com o intuito de melhorar o processo de publicidade da área de Marketing no Ministério.

\subsection{Objetivos Específicos}

- Analisar descritivamente os dados de maneira que possibilitem a comparação da atividade turística entre os destinos que participaram e os que não participaram da Campanha;

- Avaliar o retorno da Campanha para o turismo nacional em termos de cadastramento de meios de hospedagem. 


\subsection{Justificativa}

Com a modernização da Administração Pública, Faria (2005) mostra que a mudança nas relações entre Estado e sociedade e pela adoção dos princípios empreendedores da gestão pública, a avaliação de programas e políticas governamentais assumiu grande relevância para as funções de planejamento e gestão de governo. Além de ser útil para medir a eficácia da gestão pública, a avaliação também contribui para a busca e obtenção de ganhos governamentais em termos de satisfação dos usuários e de legitimidade social e política. Faria (2005) nota que a avaliação de políticas públicas tem sido uma tendência justificada pela necessidade de "modernização" da gestão pública, em um contexto de busca de dinamização e legitimação da reforma do Estado, levando-se em consideração que a mensuração de resultados possibilita rever, corrigir ações, construir uma base para a formulação de políticas posteriores, além de gerar mais conhecimento e credibilidade, contribuindo para a dinamização e legitimação supracitadas.

Ao executar um planejamento para que sejam formuladas estratégias governamentais e políticas públicas, é importante que sejam levados em consideração os resultados de ações desenvolvidas em momentos anteriores.

O critério de avaliação subjetiva tem sido muito utilizado, uma vez que cada vez mais fala-se em bem-estar social e em compreender a percepção da população sobre a adequação dos resultados objetivos dos programas aos seus desejos e necessidades. No entanto, quando tratamos de políticas que demandam recursos financeiros de origem pública, é necessário nortear a utilização destes recursos por meio de avaliações que sejam capazes de medir quantitativamente a mudança entre o antes e o depois da execução de um programa.

Dentro das diretrizes estratégicas do Governo estão políticas voltadas ao incremento da atividade turística brasileira. $O$ turismo é uma atividade socioeconômica que, ao mesmo tempo, traz bons frutos para a economia e para a integração social do país, e demanda investimentos e gastos para que possam ser desenvolvidas as ações necessárias para o estímulo do uso dessa atividade como produto de consumo pelo mercado nacional e internacional. 
De acordo com dados do Portal da Transparência ${ }^{1}$ do Governo Federal, no ano de 2008 o Ministério do Turismo utilizou $\mathrm{R} \$ 2.363 .404 .764,00$ para a execução do planejamento turístico nacional. Esse montante representa aproximadamente 2,5\% do total de $\mathrm{R} \$ 931.122 .144 .673,70$ gasto pelo Governo Federal em $2008 \mathrm{com}$ todos os Ministérios e a Presidência da República. Assim, percebe-se numericamente a relevância econômica do turismo dentro do orçamento brasileiro. Cabe, assim, o questionamento sobre o quão bem administrados são esses recursos. Devem ser levantadas questões acerca da efetividade das campanhas para que os recursos federais direcionados à divulgação do turismo no Brasil sejam absorvidos nas atividades que são, de fato, capazes de trazer algum retorno para essa atividade. Torna-se impossível construir uma boa análise a respeito do assunto e tomar decisões a respeito da utilização desses recursos quando as avaliações das campanhas ou não são realizadas ou acontecem de maneira superficial e imprecisa.

Atualmente as avaliações da efetividade das campanhas realizadas pelo Ministério para estimular o turismo vêm sendo avaliadas quanto a sua efetividade apenas em termos de comparação do mesmo grupo antes e depois do tratamento, ou da concretização da política pública. O problema da utilização desses meios para a realização da avaliação é que isso dificulta o processo de separação do efeito daquele programa ou política de outros fatores que possam ter contribuído para 0 sucesso ou fracasso da política em estudo.

O Relatório de Avaliação do Plano Plurianual, por exemplo, avalia o resultado das políticas de turismo com base em metas numéricas. Caso a meta tenha sido atingida, o programa ou política foi bem sucedido, conforme evidencia o trecho a seguir, retirado do Relatório de Avaliação do Palo Plurianual do exercício de 2009, com ano base 2008:

Meta 2: CRIAR NOVOS EMPREGOS E OCUPAÇÕES NO SETOR
TURISMO. Essa é uma meta cumulativa que se pretende alcançar 1,7
milhões de emprego no horizonte do PNT 2007-2010. A meta prevista
era de 735 mil empregos para o biênio 2007 e 2008, pelos dados do
CAGED, para esse período, foram criados 701.292 , número próximo da
meta, 95\%. Acredita-se que a crise financeira do final de 2008 tenha
impedido uma maior expansão.(BRASIL, 2009, p. 10)

Vê-se que não é verificado se o "atingimento" da meta numérica estipulada deu-se pela qualidade da formulação e execução da política ou por outros fatores

\footnotetext{
${ }^{1}$ As informações apresentadas no Portal são de responsabilidade do Órgão fornecedor dos dados (origem)
} 
quaisquer, que de alguma forma influenciaram no resultado obtido, como aumento da população, crescimento econômico, estabilidade econômica nacional e internacional, além, é claro, do instrumento de pesquisa.

Assim, as avaliações tornam-se superficiais e insuficientes para contribuírem de fato com o planejamento estratégico governamental. Os resultados obtidos não são reflexo da realidade e novas políticas, programas e, mais especificamente, campanhas serão elaboradas partindo de referências irreais, o que pode ocasionar no mau uso dos recursos públicos e a continuidade de ações que pela sua essência não são efetivas, mas que apresentaram bons resultados apenas pela imprecisão do processo de avaliação.

Dessa forma, esse trabalho traz como proposta a avaliação quantitativa de uma campanha de Marketing elaborada pelo Ministério do Turismo com o intuito principal de estimular viagens domésticas em períodos de baixa atividade turística, utilizando como foco o público da terceira idade. A medição será feita de forma que os resultados obtidos em termos de relação real custo/benefício levem em consideração fatores externos à política que possam interferir na avaliação. Esse procedimento fará com que os resultados possam ser, de fato, norteadores para a formulação de novas políticas e alteração ou continuidade das políticas já existentes. 


\section{REFERENCIAL TEÓRICO}

\subsection{Turismo}

O Estudo da Competitividade do Turismo Brasileiro - Economia do Turismo (2006) nos mostra que a relevância do turismo para a economia foi, primeiramente, ressaltada pelos países desenvolvidos, de economia de mercado; a seguir, os países socialistas, em geral, também perceberam o enorme potencial do setor, cujos efeitos multiplicadores estendem-se, em maior ou menor intensidade, a dezenas de ramos de atividade (constituíam-se exceção - e hoje não mais - a China e a Albânia).

\subsubsection{Turismo no contexto internacional}

Segundo o documento Tendências Macro do Turismo Mundial (2006), o turismo tem se destacado como uma atividade socioeconômica de relevância crescente no cenário mundial. O número de viagens realizadas em todo o mundo cresceu consideravelmente, fruto do processo de globalização, do desenvolvimento tecnológico nos transportes e nas comunicações, do aumento do tempo livre para lazer e, principalmente, do crescimento da renda. A capacidade dessa atividade em transformar o deslocamento de pessoas em renda, trabalho, integração social, desenvolvimento, entre outros, faz que essa atividade seja alvo de políticas públicas de destaque dentro do planejamento estratégico de um país, inclusive o Brasil.

$\mathrm{O}$ aumento no PIB de um país contribui e potencializa o crescimento turístico. O crescimento do turismo, inclusive, tem-se mostrado superior ao crescimento do PIB em diversos países. A Tabela 1 apresenta a taxa de criscimento dos visitantes com turismo e do PIB mundial. 
Tabela 1 - Taxa de Crescimento dos Visitantes com Turismo e do PIB Mundial (\%)

\begin{tabular}{|c|c|c|c|c|c|c|c|}
\hline & África & Américas & $\begin{array}{l}\text { Ásia } \\
\text { Pacífico }\end{array}$ & e Europa & $\begin{array}{l}\text { Oriente } \\
\text { Médio }\end{array}$ & Total & PIB \\
\hline $1960-1970$ & 12,4 & 9,7 & 21,6 & 8,4 & 11,5 & 9,1 & 4,7 \\
\hline $1970-1980$ & 11,7 & 4 & 14,2 & 4,6 & 14,9 & 5,3 & 3,9 \\
\hline $1980-1985$ & 5,7 & 0,9 & 7,3 & 2,8 & 2,5 & 2,9 & 2,7 \\
\hline $1985-1990$ & 9,6 & 7,3 & 11,5 & 5,5 & 3,5 & 6,6 & 3,6 \\
\hline 1990-1995 & 6,2 & 3,3 & 8 & 3,1 & 7,3 & 4,1 & 2,8 \\
\hline $1995-2000$ & 6,6 & 3,3 & 6,2 & 4,4 & 12 & 4,8 & 3,9 \\
\hline $2000-2004$ & 4,2 & $-0,5$ & 7,3 & 2 & 8,8 & 2,9 & 3 \\
\hline $1960-2004$ & 8,8 & 4,7 & 12,4 & 4,9 & 9,7 & 5,6 & 3,8 \\
\hline
\end{tabular}

Ainda de acordo com o documento, em receitas turísticas, o crescimento do turismo se revela ainda maior, com crescimento médio de 1960-2004 de 10,8\% a.a., com picos entre 1970-1980 (taxa de 19,5\% a.a.) e 1985-1990 (taxa de 13,7\%).

Segundo o PNT 2007/2010 (2007), as chegadas internacionais de 2006, em todo mundo, foram da ordem de 842 milhões de turistas, o que significa um crescimento médio anual de acima de $6 \%$ desde 1950 , quando se registrou um total de 25 milhões de chegadas internacionais. $O$ mercado de viagens representou, em 2004 , em torno de $30 \%$ do total das trocas internacionais de serviços comerciais, constituindo um dos seus maiores componentes.

Nesse quadro de crescimento da atividade econômica no mundo, uma tendência observada ao longo dos últimos anos é de desconcentração dos fluxos internacionais de turistas, com a inclusão de novos destinos nessas rotas. Em 1950, somente $3 \%$ das chegadas internacionais se dirigiram para fora dos 15 principais países receptores (Europa, Estados Unidos, Canadá e México). Já em 2004, 43\% do total de chegadas internacionais se realizaram fora desses 15 países receptores principais. O Gráfico 2 apresenta a evolução das chegadas de turistas internacionais no período que vai de 1950 a 2004, para os cinco maiores países receptores do mundo e para o grupo de países classificados a partir da 16ª colocação no ranking, entre os quais se encontra o Brasil. 


\section{Evolução de Chegada de Turistas Internacionais}

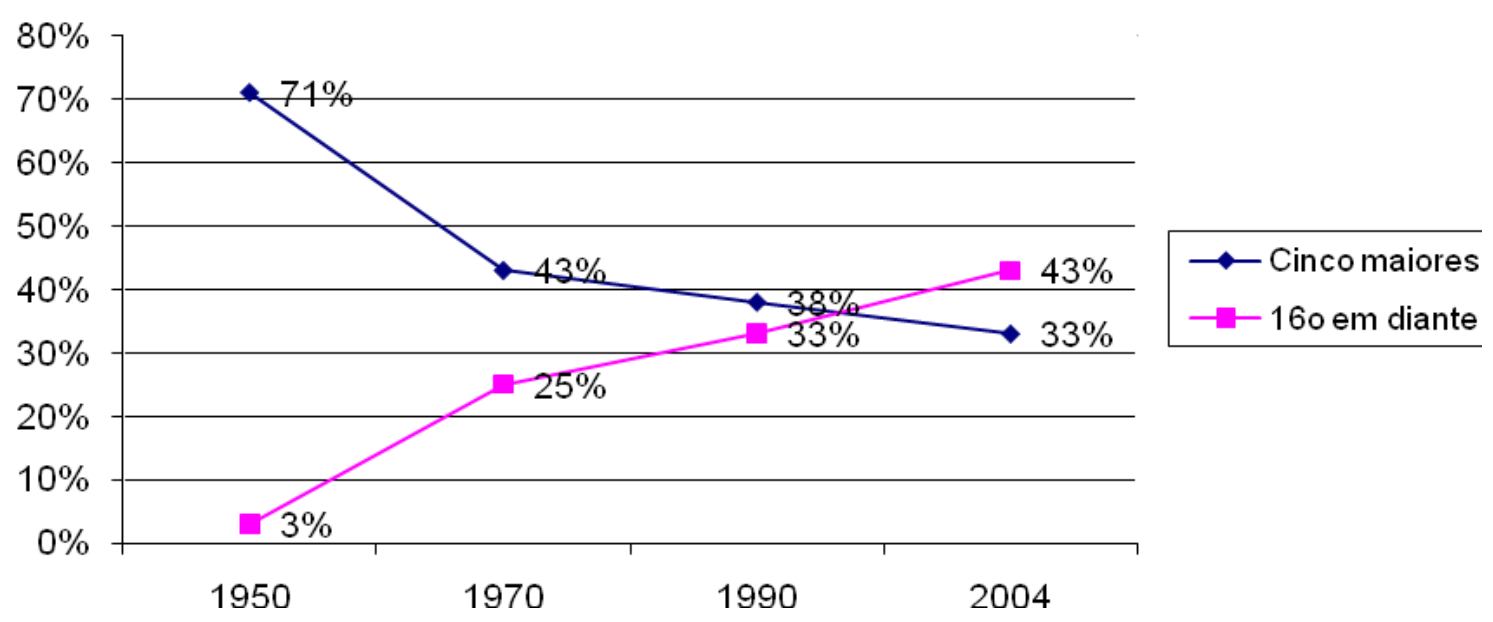

Gráfico 2: Evolução de Chegada de Turistas Internacionais Fonte: Brasil, 2007.

De acordo com a Tabela 2, enquanto as chegadas internacionais em todo o mundo tiveram um crescimento de 56,5\%, no período de 1995 a 2006, no Brasil esses números cresceram da ordem de $150 \%$ no mesmo período, apesar do decréscimo de 2005 para 2006, em função da redução na oferta de assentos em vôos internacionais decorrentes da crise da empresa aérea Varig.

Tabela 2 - Chegada de Turistas Internacionais (em milhões)

\begin{tabular}{llllllll}
\hline Período & 1995 & 2003 & 2004 & 2005 & $2006^{*}$ & $\begin{array}{l}\text { Variação } \\
\% \\
2003-06\end{array}$ & $\begin{array}{l}\text { Variação } \\
\% \\
1995-06\end{array}$ \\
\hline Mundo & 538,0 & 697,0 & 766,0 & 806,0 & 842,0 & 20,8 & 56,5 \\
Europa & 309,0 & 408,6 & 425,6 & 441,0 & 458,0 & 12,1 & 48,2 \\
Ásia e Pacífico & 85,0 & 114,2 & 145,4 & 155,4 & 167,1 & 46,3 & 96,6 \\
Américas & 109,0 & 113,1 & 125,8 & 133,5 & 136,6 & 20,8 & 25,3 \\
América do Sul & 12,0 & 13,7 & 16,0 & 18,3 & 19,6 & 43,1 & 63,3 \\
Brasil & 2,0 & 4,1 & 4,8 & 5,4 & 5,0 & 22,0 & 150,0 \\
África & 20,0 & 30,7 & 33,3 & 37,3 & 40,3 & 31,3 & 101,5 \\
Oriente Médio & 14,0 & 30,0 & 35,9 & 39,2 & 40,8 & 36,0 & 191,4 \\
\hline Fonte: Brasil, 2007 & & & & & & &
\end{tabular}

A Organização Mundial do Turismo - OMT traz análises que mostram que além da perspectiva internacional, calcula-se que o turismo interno chega a ser dez 
vezes maior que o turismo internacional. Segundo a pesquisa Caracterização e Dimensionamento do Turismo Doméstico no Brasil, esse índice é bem maior para o Brasil, o que aponta para uma perspectiva de consolidação da atividade no País, oportunizando a melhoria da qualidade dos serviços prestados e contribuindo para o desenvolvimento equilibrado do conjunto da economia.

\subsubsection{O turismo no Brasil}

O turismo no Brasil tem tido excelentes resultados em relação a todo 0 histórico do setor, aproveitando que a conjuntura interna e externa estão favoráveis (TOMIKAWA, 2009). Além do fortalecimento do mercado interno, a chegada de turistas estrangeiros também é relevante, uma vez que proporciona a geração de divisas para o País. No entanto, o turismo doméstico é o que dá à atividade a força necessária para que a oferta turística nacional seja atraente para o mercado internacional.

Segundo a pesquisa Caracterização e o Dimensionamento do Turismo Doméstico no Brasil (2005), em 2005 foram realizadas 139,59 milhões de viagens domésticas, sendo essas as viagens não rotineiras dentro do território nacional com, no mínimo, um pernoite. Comparando os resultados obtidos pela mesma pesquisa em 2001, percebe-se um crescimento de $26,5 \%$ nas viagens domésticas realizadas no período analisado.

A popularização do transporte aéreo contribuiu muito para o crescimento do número de desembarques domésticos. Segundo dados do PNT 2007/2010, de 2003 a 2006 foram registrados 156,7 milhões de desembarques domésticos no País, o que revela um aumento de 23\% em relação ao quadriênio anterior (1999/2002). Em 2005, os desembarques de vôos nacionais totalizaram 43,1 milhões, ou seja, número $17,75 \%$ vezes maior que os 36,6 milhões de passageiros desembarcados em 2004. O Gráfico 3 apresenta a evolução dos desembarques nacionais no Brasil dentre o período de 1995 a 2006. 
Desembarques nacionais

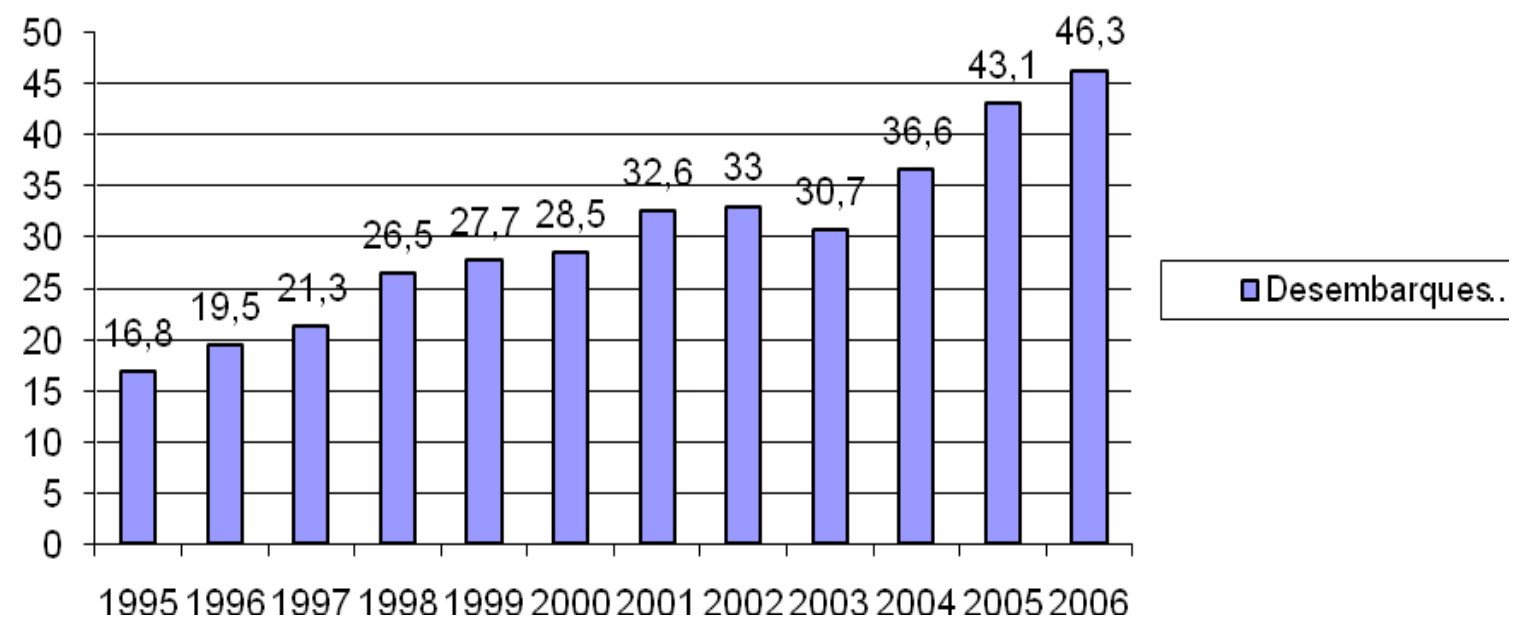

Gráfico 3: Desembarques nacionais (em milhões)

Fonte: Brasil, 2007

Além de contribuir com o crescimento da economia do País, o turismo tem relevância também pelo seu grande potencial em termos de geração de trabalho, ocupação e renda.

De acordo com dados apresentados no PNT 2007/2010, a OMT mostra que a atividade é responsável pela geração de 6 a 8 por cento do total de empregos no mundo, além de ser uma das atividades econômicas que demandam menor investimento para a geração de trabalho. Esse resultado pode ser considerado conservador, uma vez que não estão contabilizados aí dados em relação à geração de empregos informais. O Gráfico 4 ilustra essa situação, apresentando a evolução no número de empregos formais na atividade turística. 


\section{Evolução no Número de Empregos Formais na Atividade Turística (em milhões)}

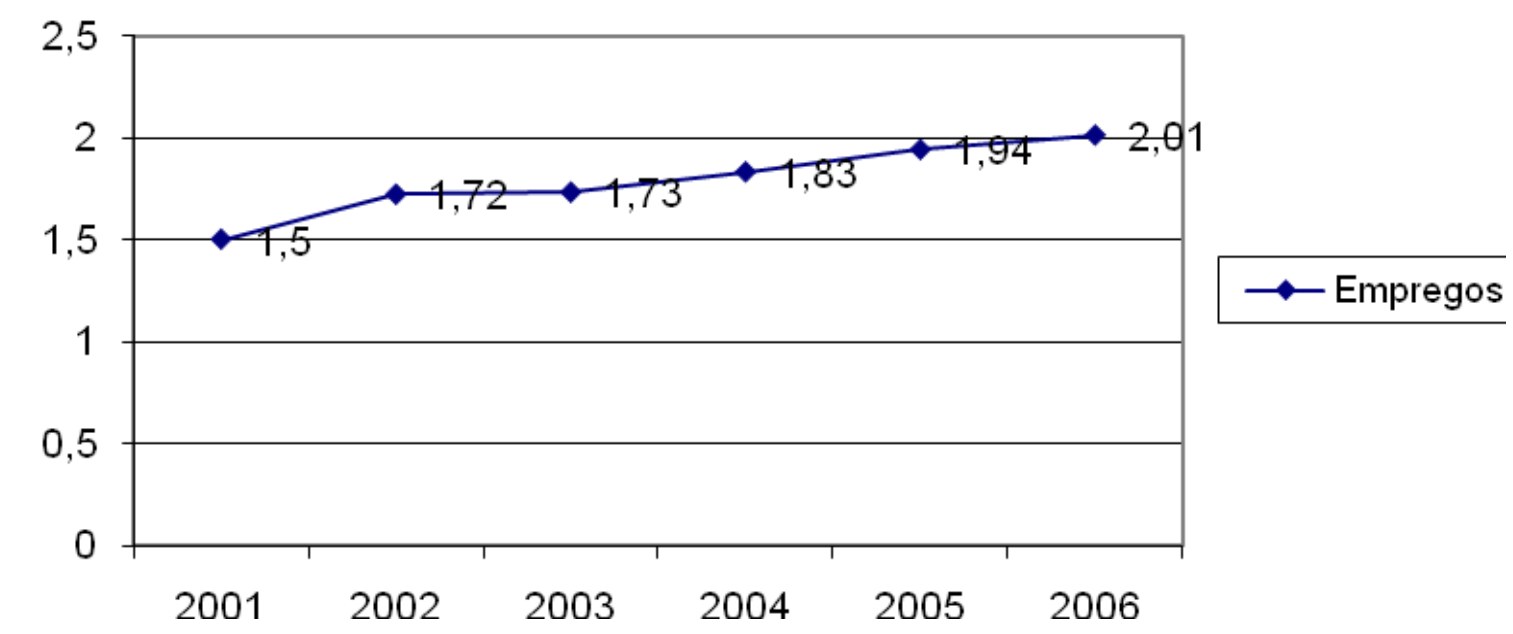

Gráfico 4: Evolução no Número de empregos Formais na Atividade Turística (em milhões) Fonte: Brasil, 2007

O Estudo da Competitividade do Turismo Brasileiro (2006), evidencia que uma das características do setor é a sazonalidade, alternando-se altas e baixas estações. Um dos objetivos das autoridades é o de que seja ampliado o tempo de permanência e gasto médio dos turistas. Nos períodos de baixa estação, a idéia é a de se promover maior número de eventos, a fim de minimizar a perda com a menor vinda de turistas. Esse fator - a sazonalidade - contribui para o aumento dos custos no turismo, por causa da não regularidade do uso de equipamentos e serviços em termos de hospedagem, transportes, utilização de estradas, entre outros.

Segundo o Relatório Executivo do Turismo Doméstico (2009), considerando-se o total anual igual a 100, se houvesse regularidade nas distribuições mensais das viagens seria de se esperar o equivalente a 8,33\% das viagens em cada um dos meses. Desta forma, o mês de Dezembro, por exemplo, respondendo por 20,0\% do total anual, na média Brasil, situa-se 140 pontos acima da média do ano. Por outro lado, os meses de Abril e Maio, com cerca de 4\%, situam-se pouco menos da metade da média anual. 
Tabela 3 - Distribuição sazonal das viagens domésticas no ano (\%)

\begin{tabular}{lllllllllllll}
\hline & Jan & Fev & Mar & Abr & Mai & Jun Jul & Ago & Set & Out Nov & Dez \\
\hline Proporção & & & & & & & & & & & & \\
das Viagens & 16,3 & 11,1 & 5,4 & 4,5 & 4,1 & 5,3 & 12,3 & 4,8 & 5,1 & 5,6 & 5,4 & 20,0 \\
Índice & de & & & & & & & & & & & \\
\end{tabular}

Sazonalidade $\left(^{\star}\right) \quad 195,9 \quad 133,3 \quad 64,4 \quad 54 \quad 49,6 \quad 64 \quad 147 \quad 57,8 \quad 61,1 \quad 67 \quad 65,3 \quad 240,6$

Fonte: BRASIL, $2009\left(^{*}\right)$ Mede a relação entre a proporção das viagens no mês e a proporção média mensal no ano.

O Relatório mostra ainda que são, portanto, considerados meses de "alta" estação aqueles que mais se distanciam para cima dos $8,33 \%$, particularmente, pela ordem: Dezembro; Janeiro, Julho e Fevereiro. Os meses de Outubro, Novembro e Março podem ser considerados quase de "média" estação. Os demais cinco meses, com 40 pontos percentuais ou mais abaixo da media, podem ser considerados de "baixa" estação, com mais destaques para Abril e Maio. Com base nestas relações, construiu-se um Indicador de Sazonalidade das principais viagens domésticas no Brasil, conforme ilustrado no Gráfico 5.

\section{Índice de Sazonalidade da Viagem Doméstica}

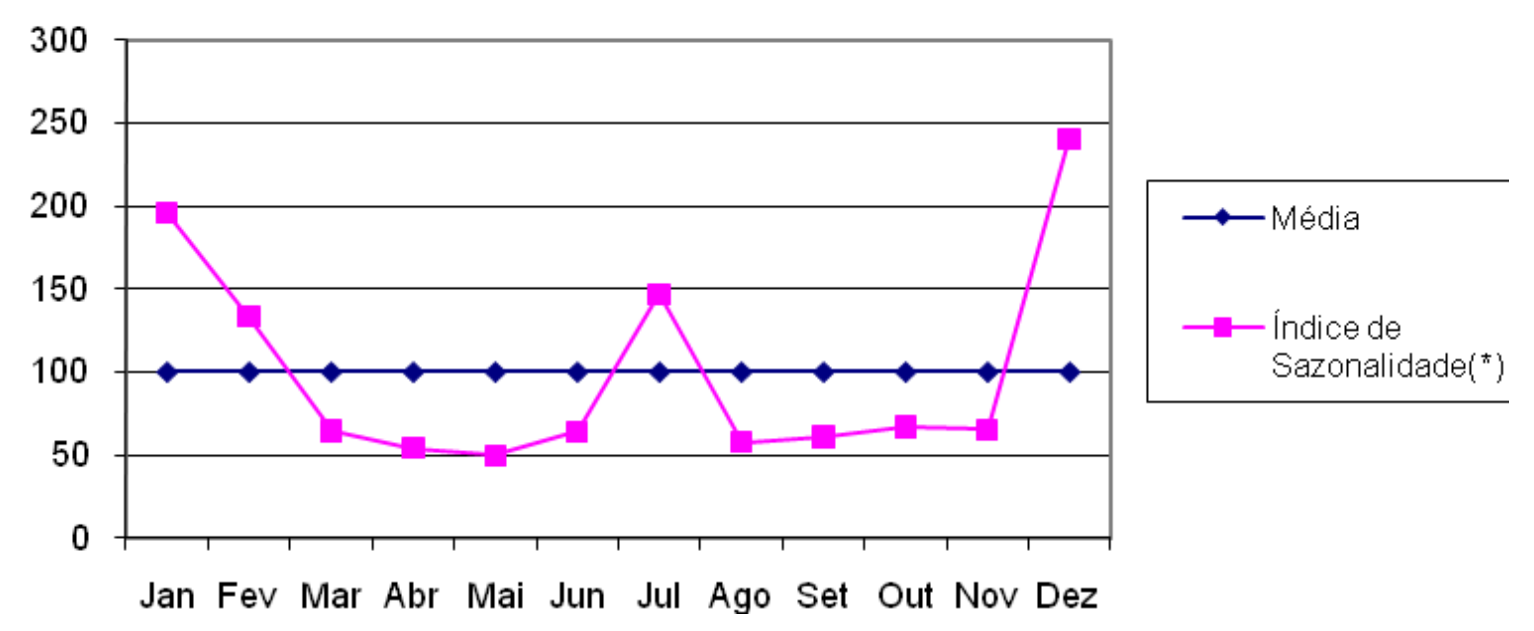

Gráfico 5: Índice de sazonalidade da viagem doméstica Fonte: Brasil, 2009.

Naturalmente, não havendo regularidade no uso dos recursos e serviços disponíveis, o custo da ociosidade acaba se refletindo no preço, o que restringiria $o$ acesso de novos consumidores e a capacidade competitiva do turismo brasileiro em relação às outras destinações turísticas. 
Nesse contexto de temporadas de alta e baixa movimentação turística e de transformação do turismo doméstico em um produto a ser cada vez mais aproveitado pelo mercado brasileiro é que o MTur criou a campanha "Viaja Mais Melhor Idade", idealizada de forma a transformar a sazonalidade em oportunidade de crescimento da atividade no Brasil. Os pacotes turísticos são vendidos para datas específicas, sempre dentro dos períodos de baixa estação.

\subsection{Políticas Públicas}

Conforme exposto ao longo deste trabalho, o turismo é uma atividade econômica com poderes de contribuir para a modificação da realidade de um país em termos de geração de empregos e renda, criação de divisas, promoção do desenvolvimento e a inclusão social, uma vez que por sua natureza agrega um conjunto de dimensões favoráveis à integração social. A movimentação de pessoas ocasionada por essa atividade, por si só, ocasiona a ruptura do isolamento, promovendo o contato entre culturas. Permite o conhecimento e a valorização de determinados ambientes e comunidades, estimulando o respeito e o interesse pela sua preservação. Assim, conforme o exposto e pela perspectiva de crescimento da atividade não apenas no Brasil, mas também no mundo inteiro, o turismo implica a composição e articulação de políticas públicas, de forma a organizar e estimular o turismo.

Em relação à conceituação de políticas públicas, Jenkins (1978 apud ALBUQUERQUE, 2009) as descreve como um conjunto de decisões interrelacionadas tomadas por um ator político ou um grupo de atores com autoridade política e que dizem respeito à definição de metas e à adoção dos meios para alcançá-las; Dias (2003) coloca a política pública como sendo o conjunto de ações executadas pelo Estado, enquanto sujeito, dirigidas a atender às necessidades de toda a sociedade.

Albuquerque (2009) coloca que as políticas públicas para o desenvolvimento do setor de turismo acontecem nas diferentes esferas do governo: municipal, regional, estadual, nacional e internacional. Assim, planejamento e intervenções são 
implementados pelos órgãos do governo, possibilitando um conjunto diverso de objetivos e resultados.

Ao trazer o conceito de política pública para o setor do turismo, Barreto (2003) coloca que o papel das políticas públicas deveria ser o de propiciar o desenvolvimento harmônico dessa atividade. Assim, caberia ao Estado construir a infraestrutura de acesso assim como a infraestrutura básica urbana. Também seria de sua responsabilidade prover à área do turismo de uma superestrutura jurídicoadministrativa (secretarias e similares) para planejar e controlar os investimentos realizados pelo Estado, para poder oferecer à iniciativa privada as devidas condições para construir e desenvolver os equipamentos turísticos e melhor desempenhar as atividades de prestação de serviços.

Assim, as políticas públicas podem ser entendidas como um aglomerado de normas e ações elaboradas e postas em prática pelo governo, em parceria com a sociedade e com a iniciativa privada. Especificamente no caso do Brasil, a relevância da atividade - já exposta ao longo deste trabalho - e o potencial de desenvolvimento da mesma justificam a formulação de políticas para organização do turismo no país.

De acordo com o projeto de pesquisa O Turismo no Brasil: Panorama Geral, Avaliação da Competitividade e Propostas de Políticas Públicas (2006), a formulação das políticas de turismo no Brasil começou com a criação da Embratur e do Conselho Nacional de Turismo, CNTur. No início dos anos setenta, as políticas de estruturação do setor tinham a preocupação de contemplar o problema do financiamento dos investimentos de longo prazo, sobretudo no setor hoteleiro. Através do DECRETO-Lei № 1.191, de 27.10.71, os negócios turísticos foram equiparados à indústria para receber incentivos fiscais e foi instituído o Fundo Geral de Turismo, Fungetur, "destinado a fomentar e prover recursos para o financiamento de obras, serviços e atividades turísticas consideradas de interesse para 0 desenvolvimento do turismo nacional". Este fundo seria formado com recursos orçamentários e com as receitas oriundas do recolhimento de taxas provenientes dos registros das empresas de turismo junto a Embratur. Este órgão seria também o gestor do fundo que passou a operar em 1976.

O mesmo projeto de pesquisa coloca que o turismo ganhou a importância de peça estratégica a partir do primeiro mandato de governo de Fernando Henrique Cardoso, que passou a ver a atividade como instrumento gerador de renda e 
emprego. Nesse período, a EMBRATUR - Instituto Brasileiro de Turismo formulou a "Política Nacional de Turismo - principais diretrizes, estratégias e programas 19961999". Esse foi o primeiro planejamento estratégico do turismo brasileiro, sendo considerado uma conquista importante em termos de implantação de políticas públicas para o turismo no Brasil. A partir de então, essa atividade econômica ganhou cada vez mais espaço dentro das prioridades do governo para 0 desenvolvimento econômico e social do Brasil.

Em 2003, no primeiro mandato do presidente Luiz Inácio Lula da Silva, foi criado o Ministério do Turismo, considerado uma das dez prioridades da gestão. Foi instituído com a missão de promover o desenvolvimento do turismo como agente de transformação, fonte de riqueza econômica e de desenvolvimento social, por meio da qualidade e competitividade dos produtos turísticos, da ampliação e melhoria de sua infra-estrutura e da promoção comercial do produto turístico brasileiro no mercado nacional e no exterior.

As políticas públicas e os instrumentos de planejamento do turismo são decorrentes das diretrizes estratégicas de governo. A implementação do atual ciclo de planejamento pelo Ministério do Turismo é processada em três Programas atendendo a três Objetivos Setoriais, que por sua vez contribuem com dois Objetivos de Governo: 1 - Promover a Inclusão Social e a Redução das Desigualdades; e, 2 Promover o Crescimento com Sustentabilidade, Geração de Empregos e Distribuição de Renda.

O Ministério do Turismo orienta-se pelas diretrizes definidas no Plano Nacional de Turismo, que estrutura um conjunto articulado de macroprogramas e programas que, alinhados com os Programas e as Ações do Plano Plurianual de Governo, estabelecem as condições para a sua efetivação no âmbito do governo federal.

O planejamento estratégico concebido para o turismo no Brasil implementou um modelo de gestão pública descentralizada e participativa, integrando as diversas instâncias públicas e da iniciativa privada, por meio da criação de ambientes de reflexão, discussão e definição das diretrizes gerais para o desenvolvimento da atividade nas diversas escalas territoriais do país, alcançando todas as regiões brasileiras e todos os setores representativos do turismo.

A nível estratégico, o sistema nacional de gestão do turismo ficou composto por um núcleo básico formado pelo Ministério do Turismo, pelo Conselho Nacional 
de Turismo e pelo Fórum Nacional de Secretários e Dirigentes Estaduais de Turismo.

O "Plano Nacional de Turismo - Diretrizes, Metas e Programas" estabeleceu os rumos para o desenvolvimento da atividade no Brasil para o período de 20032007. Esse plano seguiu os principais modelos internacionais de desenvolvimento turístico, baseados em clusters, que segundo Gutierrez e Bordas (1993 apud TOMIKAWA, 2009), "são conglomerados de vários atrativos turísticos, infraestruturas compatíveis, equipamentos e serviços receptivos, bem como a organização turística concentrada em âmbito geográfico bem definido"

A reeleição do presidente Luis Inácio Lula da Silva possibilitou a continuidade dessa política. Com esse objetivo, foi então lançado o "Plano Nacional de Turismo 2007 2010: uma viagem de inclusão" (BRASIL, 2007). O Plano Nacional do Turismo $2007-$ 2010 elabora três Objetivos Gerais, que são os Objetivos Setoriais no Plano Plurianual 2008-2011:

- Promover o turismo como um fator de inclusão social, por meio da geração de trabalho e renda e pela inclusão da atividade na pauta de consumo de todos os brasileiros;

- Desenvolver o produto turístico brasileiro com qualidade, contemplando nossas diversidades regionais, culturais e naturais; e,

- Fomentar a competitividade do produto turístico brasileiro nos mercados nacional e internacional e atrair divisas para o País.

- Esses Objetivos Setoriais apóiam, mais especificamente, dois Objetivos de Governo previstos na Orientação Estratégica de Governo - OEG para o Plano Plurianual 2008-2011:

- Promover a Inclusão Social e a Redução das Desigualdades; e,

- Promover o Crescimento com Sustentabilidade, Geração de Empregos e Distribuição de Renda.

As metas estipuladas para o PNT 2007-2010 são as seguintes:

- Promover a realização de 217 milhões de viagens no mercado interno;

- Criar 1,7 milhão de novos empregos e ocupações;

- Estruturar 65 destinos turísticos com padrão de qualidade internacional;

- Gerar 7,7 bilhões de dólares em divisas. 
De acordo com as metas estabelecidas, foram delimitados macroprogramas, que são constituídos por programas que organizam as atividades executivas da atuação ministerial e seus parceiros. Os programas se desdobram em diversas ações, que traduzem o seu detalhamento em projetos e atividades que propiciarão a realização das metas.

O presente estudo está inserido no Macroprograma Promoção e Apoio à Comercialização, que tem os seguintes objetivos:

- Fomentar o mercado interno, promovendo um número maior de produtos de qualidade;

- Possibilitar o aumento das viagens domésticas por meio de mecanismos que viabilizem a oferta de produtos acessíveis e de qualidade, possibilitando a inserção de novos grupos de consumidores nacionais;

- Promover as regiões brasileiras por meio da diversidade cultural e natural, no país e no exterior, contribuindo para a diminuição das desigualdades regionais;

- Aumentar o fluxo de turistas estrangeiros ao Brasil, realizando intensa promoção nos grandes mercados emissores internacionais; e

- Fortalecer o segmento de negócios, eventos e incentivos.

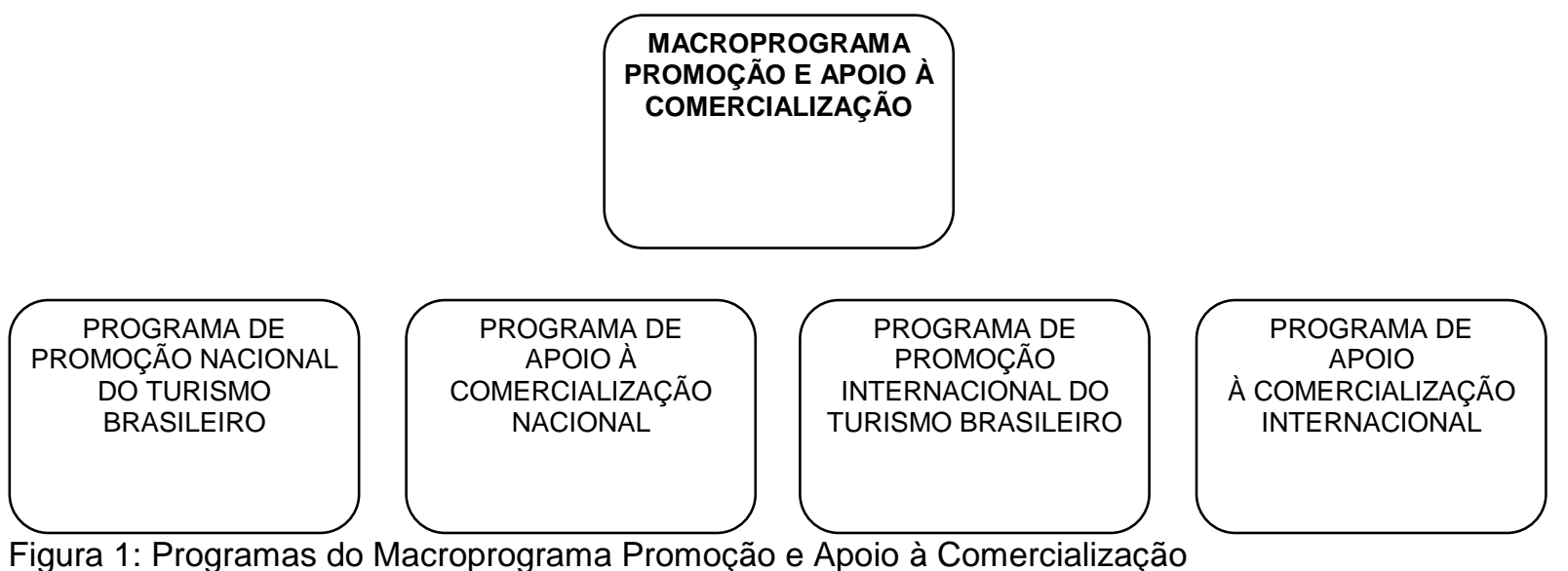

Figura 1: Programas do Macroprograma Promoção e Apoio à Comercialização Fonte: Brasil, 2007

O Programa de Promoção Nacional do Turismo Brasileiro, foco deste estudo, integra ações de propaganda, publicidade e participação em eventos que divulgam e agregam valor à imagem do destino turístico de maneira pública. Ainda no âmbito das ações de publicidade e propaganda, inserem-se também a realização 
e o apoio a campanhas para a promoção do turismo interno, de forma a motivar o brasileiro a conhecer o seu próprio país, aumentando os fluxos turísticos domésticos.

As ações de marketing, as ações promocionais e de relações públicas, com base na Marca Brasil, devem consolidar a imagem de um país moderno, com credibilidade, alegre, jovem, hospitaleiro, capaz de proporcionar lazer de qualidade, novas experiências aos visitantes, tornando-o competitivo nacional e internacionalmente. Deve ter como essência a realização de experiências positivas de conhecimento, integração e valorização das riquezas culturais e naturais do país, para a difusão e promoção de um turismo seguro, qualificado, diversificado e sustentável.

No mercado interno deve buscar promover o aumento de viagens com a inserção de novos grupos de consumidores até então excluídos desse tipo de consumo, seja por meio de propostas de programas sociais e de oferta de produtos a preços acessíveis, seja derrubando o mito de que o turismo é uma categoria de consumo exclusiva das elites nacionais e estrangeiras.

As ações de promoção no mercado interno devem trabalhar no foco da identificação dos principais centros emissores internos e dos públicos-alvos respectivos, além de incluir o turismo na pauta de consumo dos brasileiros, expandindo esse mercado a parcelas da população até então excluídas.

O Plano de Marketing Turístico Nacional - Plano Cores do Brasil foi elaborado em 2005 para ser referência na realização dos programas, ações e campanhas de promoção do mercado nacional realizadas pelo MTur (BRASIL, 2005).

\subsection{Marketing}

Marketing é uma palavra oriunda do vocábulo inglês market, que significa mercado. Cobra (2005, p. 16) coloca que:

A expressão anglo-saxônica Marketing deriva do latim "mercare", que definia $o$ ato de comercializar produtos na antiga Roma. Enquanto tudo o que se produzia era vendido, ou melhor, era comprado, não havia a necessidade de um esforço adicional de vendas, e, portanto, o marketing 
era desnecessário. Somente no século passado contatou-se a necessidade Marketing [...]

Em Melgar (2001) encontramos a abordagem de que marketing seria todo processo de compra que gira em torno de produtos, que podem ser os mais diversos, classificados em dois grandes grupos: os tangíveis e os intangíveis. Os primeiros são aqueles que podem ser tocados, e os segundos integram os produtos que não podem ser tocados. Pode-se, assim, inferir que os produtos derivados de serviços turísticos são caracterizados como intangíveis.

Ainda a respeito da definição de marketing, Kotler/Keller (2006, p. 4) coloca: "é um processo social pelo qual indivíduos e grupos obtêm o que necessitam e desejam por meio da criação, da oferta e da livre troca de produtos e serviços de valor com os outros", ou seja, é oferecer o que indivíduos e grupos precisam e fazêlos precisar do que desejam.

\subsubsection{Marketing turístico}

Ao longo do estudo, é possível perceber que a atividade turística enquadrase hoje como parte da produção massiva de bens e serviços. Castelli (1984) coloca que um consumo em massa exige que seja articulada uma produção também em massa, e que para ajustar este consumo à produção é que surgiu o marketing turístico. Assim, Ruschmann (1995) coloca que o turismo possui características específicas, que requerem técnicas mercadológicas também específicas - o marketing turístico -, e que estão sendo estudas no Brasil, no entanto, ainda de forma incipiente.

Esse marketing turístico é relatado por Krippendorf (2003) como a adaptação sistemática e coordenada da política das empresas de turismo, tanto privadas como públicas, nos planos local, regional, nacional e internacional, tendo por propósito a plena satisfação das necessidades de determinados grupos de consumidores.

Em Tomikawa (2009), enumera-se os fatores para o atraso no desenvolvimento do marketing turístico:

- O fator humano: no início, as pessoas que trabalhavam em turismo easseguravam seu êxito eram aquelas que conheciam bem a região, mas não possuíam formação especializada. A hotelaria foi a primeira área do turismo e 
perceber a necessidade de capacitação, sendo criadas instituições de ensino para preencher essa lacuna. Entretanto, a criação de cursos de graduação e pós-graduação não evitou que o setor continuasse a atuar de forma empírica. Além disso, a qualidade desses cursos segue sendo questionada.

- O meio: a atividade turística é conduzida basicamente por empresas privadas, associações e poder público. Entre estas entidades, nem sempre existiram interesses e visões comuns, o que dificultou a necessária integração para o surgimento do marketing turístico.

- A estrutura: na maioria dos países, o que existia no passado era um órgão de turismo encarregado de organizar o setor. Este organismo oficial, mediante instrumentos legais e de uma política turística, procurava ajudar os participantes do Sistema de Turismo, mas nem sempre se podia alcançar o necessário espírito de solidariedade para uma ação conjunta dos diferentes elementos do setor. Isto devido às diferenças de ordem jurídica entre os componentes do sistema (empresas privadas, mistas e estatais), que originavam as diferenças na capacidade de resposta e rapidez de execução, o que repercutiu no desenvolvimento do marketing.

- Os recursos financeiros: em quase todos os países receptores, os recursos financeiros de que se dispunham para aumentar o turismo eram e até hoje são limitados e muitas vezes mal administrados. 


\section{MÉTODOS E TÉCNICAS DE PESQUISA}

\subsection{Tipo e descrição geral da pesquisa}

Para o processo de investigação científica, é necessário que esclareçamos, em primeiro lugar o conceito de ciência. De acordo com Dencker (1998, p. 18), "ciência é uma forma especial de conhecimento da realidade empírica. É um conhecimento racional, metódico e sistemático, capaz de ser submetido à verificação". Ou seja, para que um conhecimento seja considerado científico, faz-se necessária a utilização de um método.

A Organização Mundial de Turismo define metodologia turística como o "conjunto de métodos empíricos experimentais, seus procedimentos, técnicas e táticas para ter um conhecimento científico, técnico ou prático dos fatos turísticos" (DENCKER, 1998). Dentro desse processo, a metodologia científica é uma ferramenta capaz de orientar as ações a serem realizadas.

Apesar de ser uma atividade antiga, apenas recentemente a produção científica em turismo começou a crescer. De acordo com Sakata (2002), a discussão sobre métodos de pesquisa mais adequados na área vem ocorrendo em diversos países, porém, a literatura sobre esse assunto em língua portuguesa ainda é limitada.

Dentre os três tipos de delineamento existentes - exploratório, descritivo, explicativo e experimental -, a pesquisa a ser desenvolvida pode ser enquadrada como exploratória/experimental, ou seja, busca o aprofundamento de conceitos preliminares sobre determinada temática. Assim, contribui para o esclarecimento de questões superficialmente abordadas anteriormente sobre 0 assunto. $O$ enquadramento mencionado acima é justificado pela proposta do estudo em trazer novos tipos de análise, no caso aplicadas ao turismo e por buscar determinar um objeto de estudo, selecionar as variáveis capazes de influenciá-lo e definir o efeito que a variável produz no objeto.

Em relação à abordagem do problema, a pesquisa enquadra-se como quantitativa, aquela caracterizada pelo uso de instrumentos estatísticos, tanto na 
coleta quanto no tratamento dos dados. "Caracteriza-se pelo emprego de quantificação tanto nas modalidades de coleta de informações quanto no tratamento delas por meio de técnicas estatísticas." (RICHARDSON, 1999, pg 70). A bordagem qualitativa é expressa usando linguagem e imagem, enquanto a abordagem quantitativa é expressa em termos numéricos (COZBY, 2009).

A maioria das técnicas estatísticas é desenvolvida considerando dados provenientes de uma amostra aleatória, ou seja, aquelas amostras nas quais cada elemento da população tem a mesma probabilidade de pertencer à amostra (SELLTIZ; WRIGHTSMAN; COOK, 1987). Por exemplo, a população de jovens menores de 18 anos que moram no Plano Piloto têm igual chance de serem incluídos no estudo.

Torna-se claro, assim, a não aleatorização da amostra a que se refere esse estudo. As Unidades da Federação contempladas na campanha são escolhidas para participar de acordo com suas características em termos de atrativos ou relevância para a atividade turística. Como alternativa para situações com a descrita, em que não se tem o grau de controle de um delineamento experimental, surgiram os delineamentos quase-experimentais (COZBY, 2009). Esses delineamentos tentam atingir um grau de controle próximo ao dos delineamentos experimentais, para inferir que determinado tratamento teve o efeito pretendido.

Assim, a estimação do impacto da participação na campanha sobre o turismo de terminada UF exige que sejam comparadas UFs "comparáveis", ou seja, UFs cujas características que determinam a participação na campanha sejam, por hipótese, semelhantes, o que traria equivalência em relação à distribuição aleatória do tratamento. Dessa forma, a estratégia para a identificação escolhida para esse estudo foi a de calcular a propensão de uma determinada UF a participar da campanha, ou seja, o Propensity Score. Isso para selecionar, dentre todas os estados, as UF's não-contempladas com a campanha semelhantes em características observáveis das UF's contempladas.

Seguindo o modelo proposto no artigo Aspectos Conceituais e Metodológicos da Avaliação de Políticas e Programas Sociais publicado em 2009 pela IPEA - Instituto de Pesquisa Econômica Aplicada (RAMOS, 2009), a pesquisa terá a sua avaliação desenhada de forma a trazer informações antes e depois do tratamento, além da divisão da amostra em dois grupos comparativos: o que foi atingido pela política e o grupo de controle, ou seja, aquele que não foi atingido pela 
política. Para isso, a população definida será agrupada conforme similaridade de variáveis. Dentre os mais similares, serão separados os dois grupos conforme citado acima: os que foram alvo da política pública e os que não foram atingidos pela mesma. Isso porque, conforme evidencia a metodologia proposta, caso seja analisado somente o grupo que foi afetado pela política antes e depois do tratamento, será mais difícil separar o impacto daquela política do efeito de outros aspectos que interferem no resultado que está sendo investigado.

\subsection{Caracterização do objeto de estudo}

A campanha de marketing "Viaja Mais Melhor Idade", mencionada ao longo desse estudo, pode ser considerada como um esforço de uma entidade pública brasileira em aproveitar o marketing como uma ferramenta de promoção do turismo.

Essa campanha surgiu para estimular as viagens domésticas em períodos de baixa ocupação. O programa começou com a organização e comercialização de pacotes customizados para a terceira idade, além da concessão de uma linha de crédito consignado para estimular as viagens desse público (BRASIL, 2010).

Além da venda de pacotes fora de época, o programa pretende ainda promover a inclusão social de idosos, aposentados e pensionistas, democratizando o acesso ao turismo na melhor idade e fazendo com que mais brasileiros conheçam a diversidade cultural do país, além de contribuir para o alcance da primeira meta do PNT 2007/2010, que é a de estimular a realização de 217 milhões de viagens no mercado interno até 2010.

O turista com idade superior a 60 anos possui mais flexibilidade para administrar o seu tempo, fato que se ajusta às políticas do Ministério do Turismo, uma vez que visam a criação de mecanismos para diminuir a ociosidade dos recursos turísticos em períodos de baixa ocupação. Deste modo, enquanto os destinos turísticos diminuem a variação sazonal, os idosos podem ter acesso a viagens apelo Brasil por preços mais acessíveis.

A proposta da campanha é bastante interessante e, superficialmente, vem sendo medida em termos de resultados apenas com base no crescimento do número de pacotes vendidos após a realização da campanha. 
Abaixo segue a apuração dos resultados conforme realizada pelo Ministério do Turismo:

- No primeiro ano, de agosto a novembro de 2007, foram vendidos nove mil pacotes - 30\% a mais que a meta estabelecida pelo MTur, com saídas apenas de Brasília e São Paulo, para 12 destinos. À época, o programa funcionava com 13 operadoras cadastradas e 890 agências credenciadas.

- Em 2008, a projeção de venda anual de 50 mil pacotes nos dois períodos (fevereiro a junho e agosto a novembro), mas a procura foi surpreendente: foram comercializados $180 \mathrm{mil}$ pacotes (março a dezembro/2008), ultrapassando o triplo da meta.

- Em 2009, foram vendidos 180 mil pacotes. Atualmente, o programa conta com 13 cidades de origem emitindo turistas da terceira idade para 36 destinos receptores. Há 13 operadoras de turismo e 1.582 agências cadastradas, com representação em todas as UF's brasileiras, colocando à disposição desse público cerca de 400 pacotes diferenciados. Um cálculo superficial, com preço médio de $\mathrm{R} \$ 900,00$ por pacote, indica uma movimentação financeira de aproximadamente $R \$ 300$ milhões - excluindo, ainda, o faturamento indireto da cadeia beneficiada.

Tabela 4: Destinos mais procurados, por ordem de interesse/venda

Destinos mais procurados, por ordem de interesse/venda

\begin{tabular}{ll}
\hline $1^{\circ}$ & Caldas Novas-GO \\
$2^{\circ}$ & Serra Gaúcha-RS \\
$3^{\circ}$ & Fortaleza-CE \\
$4^{\circ}$ & Maceió-AL \\
$5^{\circ}$ & Salvador-BA \\
$6^{\circ}$ & Gravatal-SC \\
$7^{\circ}$ & João Pessoa-PB \\
$8^{\circ}$ & Porto Seguro-BA \\
$9^{\circ}$ & Itapema-SC \\
$10^{\circ}$ & Lins-SP
\end{tabular}

Fonte: MTur, 2010 
Percebe-se, assim, que as análises de resultados elaboradas pelo órgão para julgar se uma política, programa ou campanha, está sendo bem sucedida em sua proposta inicial ainda são superficiais e não podem ser consideradas referências para a tomada de decisão em termos de orientação de gastos públicos, opção por continuidade ou não da campanha, entre outros.

É com base nesse cenário que fica evidenciada a carência de estudos quantitativos científicos na área, que partam de algum modelo teórico, utilizem um método e desenvolvam uma técnica para eficiência ou até mesmo com a utilidade da pesquisa, já que análises como as mostradas acima, em termos de base para tomada de decisões estratégicas, não significam muita coisa.

\subsection{População e amostra}

A população do estudo foi formada por todas as Unidades Federativas do território brasileiro, de forma que foi possível compará-los tendo por base fatores observáveis, conforme propõe a metodologia escolhida para o desenvolvimento do trabalho.

Assim, fizeram parte do estudo as UFs brasileiras: Distrito Federal, Santa Catarina, São Paulo, Rio Grande do Sul, Rio de Janeiro, Paraná, Mato Grosso do Sul, Goiás, Mato Grosso, Minas Gerais, Espírito Santo, Amapá, Roraima, Rondônia, Pará, Amazonas, Tocantins, Pernambuco, Rio Grande do Norte, Ceará, Acre, Bahia, Sergipe, Paraíba, Piauí, Alagoas e Maranhão, cujos dados encontram-se no apêndice do presente estudo.

A amostra foi formada pelas Unidades Federativas que mais se assemelham nas variáveis coletadas, de acordo com o que propõe a metodologia em questão. $O$ trabalho em questão é composto utilizando-se a população de UF's, ou seja, nesse caso não haveria amostra. No entanto, devido à necessidade de randomização do propensity score, uma amostra será sorteada e a sua representatividade será avaliada a posteriori por meio do Erro-Padrão do modelo. 


\subsection{Procedimentos de coleta e de análise de dados}

Ao se estudar a relação entre duas variáveis, imagina-se que elas tenham uma relação de causa e efeito. A variável independente é a variável manipulada pelo pesquisador e a variável dependente é o comportamento medido, causado pela variável independente (COZBY, 2009). Trazendo esse conceito para o experimento deste estudo, tem-se que os procedimentos de pareamento são implementados utilizando-se um escore balanceado, computado a partir de um modelo de regressão logística simples, onde a variável dependente é a participação na campanha: $1=$ participou e $0=$ não participou. Especificamente usa-se o logaritmo das chances de participar (log odds). Estima-se um modelo logit utilizando todas as variáveis observadas como preditoras para obtermos a probabilidade predita e computar a razão das chances (log odds - ratio) para cada observação na amostra do grupo de controle e do grupo de tratamento.

Basicamente o procedimento desta técnica testa se os escores de propensão a participar, tendo como variáveis independentes algumas características observadas, são estatisticamente os mesmos no grupo de controle e no de tratamento. Se não forem, o processo continua, com a retirada de unidades que estão mais distantes, até que tenhamos um equilíbrio nas observações. Uma vez que haja certo equilíbrio, isto é, que as unidades estejam comparáveis, podemos efetuar o teste de diferença de médias, da nossa variável que se refere ao resultado do programa que estamos querendo estimar, entre o grupo de controle e o de tratamento.

As varáveis independentes seriam, então, características observáveis das UF's brasileiras: área, número de municípios, população estimada, população com 60 anos ou mais, PIB per capita, índice de Gini, IDH, número de agências de turismo cadastradas no Mtur, participação relativa entre os estados mais emissores e mais receptores de turistas, uma dummy se a UF é litorânea ou não e os meios de hospedagem cadastrados no MTur.

Para esse estudo, assume-se que um aumento no número de meios de hospedagem cadastrados no Ministério do Turismo seria reflexo dos efeitos da campanha, uma vez que por causa dos resultados trazidos pela mesma em termos de número de turistas por meio de hospedagem, mais meios de hospedagem teriam 
o interesse em se cadastrar no Ministério a fim de poder se tornar alvo da campanha.

Um conceito importante dentro desta técnica é a idéia de um suporte comum, que se constitui na região onde o equilíbrio dos escores de propensão, entre os grupos de controle e de tratamento, se apresenta. Esta região de suporte comum é obtida a partir do descarte daqueles casos que estiverem muito abaixo ou muito acima da média dos escores. Entretanto, este procedimento de descarte dos casos que estiverem fora da região de suporte comum pode causar alguns problemas, como: bons pares podem ser perdidos próximo aos limites da região de suporte comum e a exclusão de casos pode mudar os parâmetros a serem estimados (redução do tamanho da amostra).

Pelo fato de esta técnica se basear nas características observáveis, ela apresenta certa limitação no que diz respeito às características não observadas que podem estar na base de processos de seletividade. Contudo, a literatura sobre esta técnica (HECKMAN; ISHIMURA; TODD, 1998) enfatiza que uma estratégia de avaliação que consegue controlar rigorosamente as características observadas e que consegue informações sobre o grupo de controle e o de tratamento de forma semelhante pode permitir estimadores confiáveis do impacto de um programa.

O que exatamente este procedimento faz é calcular a propensão (probabilidade) a participar baseado em características observáveis, após o que é feito o cálculo do valor estimado (y) na equação para todos os sujeitos (participantes e não-participantes), isto é, com base nos coeficientes da regressão logística somam-se as características de cada indivíduo (multiplicando-se pelo valor dos coeficientes da regressão) e cada indivíduo terá um valor de y diferente (um escore). Ressaltamos que para cada indivíduo no grupo participante do programa o pesquisador quer encontrar o indivíduo no grupo de controle (não-participante) que apresenta o escore de propensão mais próximo (medido pela diferença absoluta entre os escores). Este procedimento se chama "vizinho mais próximo" (nearest neighbor).

Após este procedimento não há mais necessidade de uma análise de regressão com variáveis de controle, basta fazer um teste de diferença de médias do resultado que queremos observar. 


\subsection{Experimentação utilizando Propensity Score Matching}

O desenvolvimento de políticas gera a necessidade de metódos confiáveis que mostrem se a intervenção teve (ou está tendo) o efeito pretendido. "Deveria haver, portanto, um íntimo relacionamento entre formulação de políticas efetivas e as análises de impacto" (NSAAH, 2006, p. 2, tradução nossa). Os métodos efetivos de avaliação produzem informações confiáveis sobre o que funciona e o porquê, fato permite aos formuladores de políticas utilizarem tais informações para modificar ou cancelar programas que não sejam efetivos e fazer mais com os recursos que são limitados (NSAAH, 2006). Assim, surge o conceito de propensity score matching (PSM). Esse conceito foi originado por Rosenbaum e Rubin (1983) e pode ser definido como um algorítimo que casa a probalilidade a participar da política ou tratamento (propensity score) do grupo tratado e do grupo não-tratado, ou grupo de controle.

Esse conceito deve ser usado em estudos de efeitos causais, ou seja, aqueles nos quais pretende-se avaliar uma relação temporal da causa e do efeito (COZBY, 2009). Para que possam ser feitas relações causais sobre os efeitos de um tratamento experimental, é essencial que seja feita uma distribuição aleatória, com o objetivo de equiparar dois ou mais grupos antes de iniciar o tratamento experimental (SELLTIZ; WRIGHTSMAN; COOK; 1987). Isso porque, nesses casos, o experimentador pode estar razoavelmente seguro de que as diferenças que aparecem, ao final do experimento, entre os dois grupos, são o resultado dos tratamentos e não o resultado de algumas diferenças preexistentes entre eles. $O$ propensity score aparece justamente para ajustar essa questão. Por causa da evidente necessidade de randomização dos grupos integrantes da pesquisa, resultados de experimentos nos quais os grupos podem apresentar diferenças por fatores observáveis a priori do experimento, provavelmente não serão capazes de refletir a realidade da política estudada. Não seria possível concluir se a diferença no resultado obtido com o grupo tratado e com o grupo não tratado é reflexo da política ou dessas características antes observadas.

Assim, o propensity score é uma técnica que deve ser utilizada em situações nas quais os participantes do experimento não podem ser distribuidos 
aleatoriamente, necessitando que seja calculada a propensão de cada um a participar daquela política ou programa.

Encontrando um grupo de controle que seja comparável ao grupo de tratamento, por meio do cálculo do propensity score dos dois grupos a partir de suas características observáveis, a participação no tratamento pode ser considerada aleatória (TAVARES, 2008). No caso desse estudo, um bom grupo de controle seria formado por UF's que não tenham sido alvo inicial da campanha, mas que sejam bastante semelhantes às UF's contempladas, em termos de características observáveis.

\subsubsection{Método de pareamento}

Métodos de pareamento podem ser enquadrados dentro do contexto de estimativas não-paramétricas, na relação entre uma variável para a unidade i (yi), uma variável dummy indicando a participação no programa (di) e um grupo de outras características (xi), também referidas como covariáveis e que são consideradas exógenas, uma vez que não são afetadas pela intervenção (ROSENBAUM, RUBIN, 1983). Essa relação pode ser exprimida como $y i=f(d i, x i)$, de forma que a comparação possa ser feita entre os resultados do grupo que participou $(d i=1)$ e 0 grupo não-participante $(\mathrm{di}=0)$. Para revelar estimativas consistentes acerca do impacto do programa, os métodos de pareamento assumem que não há diferença entre as características observáveis do grupo de controle e do grupo de tratamento (NASSAH, 2006).

Assim, torna-se necessário encontrar, para cada participante, um ou mais não-participantes com os mesmos valores nas observáveis. Para que o pareamento seja factível, serão encontrados indivíduos no grupo de controle com os mesmos valores de covariáveis do participante, de acordo com o seguinte (ROSENBAUM, RUBIN, 1983):

$$
p(x)=\operatorname{Pr}(d=1 \mid x)<1
$$


Assumindo o conceito de seleção por características observáveis, o pareamento requer que sejam selecionados, a partir do grupo de não-participantes, um grupo comparativo, cuja distribuição de características observáveis seja a mais similar possível em relação ao grupo participante.

Os passos básicos para a implementação do PSM (SIANESI, 2001) são:

- uma variável dummy identificando os participantes e nãoparticipantes;

- o efeito a ser avaliado;

- um grupo de covariáveis.

Em primeiro lugar, estima-se os propensity scores das covariáveis utilizando probit ou logit. Em segundo lugar, faz-se o pareamento de cada participante i com um grupo de não-participantes comparáveis (com base nos propensity scores). Finalmente, estima-se o resultado do participante i em relação aos resultados de seus vizinhos do grupo de comparação..

Nssah (2006) coloca que, sendo c(pi) o grupo de vizinhos de i no grupo comparativo, então o resultado pareado pode ser definido pela seguinte expressão:

$$
\hat{y_{i}}=\sum_{j \in c\left(p_{i}\right)} w_{i j} y_{j} ; w_{i j} \in[0,1] ; \quad \sum_{j \in c\left(p_{i}\right)} w_{i j}=1
$$

Esta seria a melhor tentativa em supor o que o participante i teria experimentado caso não tivesse sido alvo do programa.

Ainda segundo o mesmo autor, a especificação de um algorítimo pareado é baseada em duas considerações chave: cada método requer a definição de uma medida de proximidade, para identificar os não-participantes que são aceitavelmente próximos (em termos de propensity score) de qualquer outro dado participante. Este é o critério que determina c(pi), o conjunto de vizinhos de i no grupo comparativo. Finalmente, deve-se selecionar uma função de peso, que determine o peso a ser designado para cada membro de uma vizinhança na computação do resultado pareado de acordo com a equação acima.

De um modo geral, avaliadores de pareamento do impacto médio de um tratamento nos elementos tratados assume a seguinte forma: 


$$
\theta_{M}=\sum_{i \in T} \omega_{i}\left(y_{i}-\sum_{j \in c\left(p_{i}\right)} w_{i j} y_{j}\right)=\sum_{i \in T} \omega_{i} g_{i}
$$

Na qual T é o grupo de tratados e wi pode ser interpretado brandamente como o peso de avaliação designado ao participante i.

\subsubsection{Nearest-Neighbor Marching (pareamento pelo vizinho mais próximo)}

Para cada participante I, esse método procura pelo participante j com o propensity score mais próximo. Baseando-se nesse conceito, a vizinhança relevante é definida pela expressão:

$$
c\left(p_{i}\right)=\left\{j \mid \min _{j}\left\|p_{i}-p_{j}\right\|\right\}
$$

Para a aplicação do método, utilizou-se o programa STATA, que possui a rotina psmatch2. Ela realiza a obtenção dos pares e calcula o valor do ATT (avarege effect os the treatment on the treated). O método consiste na determinação do chamado contrafactual, um suposto grupo de controle pareado (com as mesmas características multivariadas dos tratados), mas que, no entanto, não receberia o efeito do tratamento. Através da diferença média da variável resultado dos pares (tratados e controles) obtém-se o ATT, uma estimativa do efeito da política com a redução do viés de seleção por controle das características observáveis.

Assim, como variáveis independentes foram consideradas as características observáveis das UF's: área geográfica, número de municípios, população estimada, população com 60 anos ou mais, PIB per capita, índice de Gini, IDH, número de agências de turismo cadastradas no MTur, participação relativa entre os estados mais emissores e mais receptores de turistas, uma dummy se a UF é litorânea ou não e os meios de hospedagem cadastrados no MTur. A variável dependente é, portanto, a participação ou não no programa. 
Considerou-se, para efeitos de resultado, que o aumento no número de meios de hospedagem cadastrados do Ministério do Turismo seria reflexo da Campanha. Somente os meios de hospedagem cadastrados no Ministério podem ser contemplados no Programa. Ou seja, o sucesso da Campanha faria com que mais donos de meios de hospedagem cadastrassem seus empreedimentos no Ministério. 


\section{RESULTADOS E DISCUSSÃO}

A partir dos procedimentos descritos nos tópicos acima, foram testados os modelos ideais para que se chegasse o mais próximo possível ao objetivo proposto pelo presente estudo.

A Tabela 5 apresenta as estatísticas básicas para a amostra. Observa-se que a média da população é de 7.090.541,85, a média da população com 60 anos ou mais é de 9,56\%, o PIB per capita médio é de 12.241,44 e a média de meios de hospedagem cadastrados no MTur em 2008 é de 139,44.

Tabela 5 - Estatísticas básicas da amostra

\begin{tabular}{lcccc}
\hline & $\begin{array}{c}\text { Pop. Estimada } \\
2009\end{array}$ & $\begin{array}{c}\text { Pop. Com 60 anos } \\
\text { Ou mais }(\%)\end{array}$ & $\begin{array}{c}\text { PIB Per capita } \\
(2007)\end{array}$ & $\begin{array}{c}\text { Meios de hospedagem } \\
\text { cadastrados no Mtur (2008) }\end{array}$ \\
\hline Média & $7.090 .541,85$ & 9,56 & $12.241,44$ & 139,44 \\
por UF & 41.348 .039 & 14,9 & $40.696,08$ & 1 \\
Máximo & 421.499 & 4,8 & $4.661,56$ & 657 \\
Mínimo & & &
\end{tabular}

Fonte: Elaboração do autor

A Tabela 6 apresenta a frequência da amostra quanto a ser uma UF litorânea e a participação ou não da campanha "Viaja Mais Melhor Idade". Do total de Unidades Federativas, 63\% são litorâneas e 70\% não participou da primeira edição da Campanha.

Tabela 6 - Frequência das variáveis dummies

\begin{tabular}{lcccc}
\hline & Litorânea & \multicolumn{3}{c}{ Participou } \\
\hline Frequência & sim & não & sim & não \\
Percentual & 0,63 & 10 & 8 & 19 \\
\hline Fonte: Elabosão & 0,37 & 0,30 & 0,70 \\
\hline
\end{tabular}

Fonte: Elaboração do autor

O primeiro passo foi a seleção das variáveis independentes que deveriam ser incluídas no modelo Logit. Como mencionado anteriormente, esse modelo foi utilizado para calcular a probabilidade das UFs a serem alvo da campanha elaborada pelo MTur. Em seguida, estas UFs foram agrupadas ou pareadas de acordo com o valor do escore de propensão. A Tabela 7 apresenta as 12 variáveis utilizadas no modelo Logit. 
Tabela 7 - Variáveis utilizadas no modelo Logit

\begin{tabular}{ll}
\hline \multicolumn{1}{c}{ Variável } & \multicolumn{1}{c}{ Descrição } \\
\hline Área (km2) & Área total da UF \\
Municípios & $\begin{array}{l}\text { Quantidade de municípios por UF } \\
\text { Pop. 2009 }\end{array}$ \\
$\begin{array}{l}\text { Pop. Com 60 anoşão estimada para o ano } \\
\text { Ou mais (\%) }\end{array}$ & População com 60 anos ou mais \\
PIB Per capita (2007) &. \\
Índice de Gini 1991 &. \\
IDH 2000 & No de agências de turismo \\
Agências & cadastradas no MTur em '03, '04, '05 \\
& $\begin{array}{l}\text { Participação relativa entre UF's } \\
\text { emissivas e receptivas de turistas }\end{array}$ \\
Participação relativa entre UF's & Dummy se a UF é litorânea ou não \\
Litorânea & No de meios de hospedagem \\
Meios de hospedagem & cadastrados no MTur em '06, '07, '08 \\
Participação na campanha & Dummy se a UF foi ou não alvo da \\
& campanha \\
\hline
\end{tabular}

Fonte: Elaboração do autor

Para o cálculo do propensity score foi utilizado como outcome a quantidade de meios de hospedagem cadastrados no MTur em 2008, uma vez que seria a variável com o efeito acumulado da campanha ao longo dos anos de 2007 e 2008. Utilizando o comando psmatch2 do STATA, foi calculado o resultado para o modelo propensity score estimado. Foram realizadas várias tentativas, com o intuito de obter o modelo com o maior número de variáveis possível, o que tornaria melhor o ajuste do modelo. No entanto, o objetivo desse trabalho é o de encontrar o modelo mais significativo, ou seja, aquele com o melhor poder de explicação. Para isso foram realizadas inúmeras combinações de variáveis como tentativa de encontrar um modelo com o menor número de variáveis e a melhor explicação.

Ao testar o modelo com todas as observações, não foi encontrada nenhuma variável que apresentasse resultado de $p$-valor com significância menor do que $10 \%$, o que descartaria o modelo como fonte de conclusões a respeito da efetividade ou não da camapanha realizada. $O$ mesmo ocorreu com diversas combinações de variáveis independentes.

Foi utilizada então uma nova variável: novaHospedagem08. Essa variável seria uma tranformação de Hospedagem08, calculada a partir do seu logarítimo, com o intuito de tentar aproximar os dados a uma distribuição normal. Ou seja: 
novaHospedagem08=log(Hospedagem08). O resultado $p$-valor com essa variável também não foi significativo. A Tabela 8 apresenta os resultados obtidos para o teste no qual foram utilizadas todas as observações:

Tabela 08 - Resultados da análise logística que estima os escore de propensão para pareamento com todas as observações

\begin{tabular}{|c|c|c|c|c|c|c|}
\hline \multicolumn{5}{|c|}{ Log da probabilidade $=-4.353 e-07$} & $\begin{array}{l}\text { No observ. = } \\
\text { LR qui2(11) } \\
= \\
\text { Prob > qui2 } \\
= \\
\text { Pseudo R2 } \\
=\end{array}$ & $\begin{array}{r}27 \\
32.82 \\
0.0006 \\
1.000\end{array}$ \\
\hline Participou & Coef. & $\begin{array}{c}\text { Erro- } \\
\text { padrão }\end{array}$ & z & $\mathrm{P}>|\mathrm{z}|$ & \multicolumn{2}{|c|}{ [95\% Intervalo conf] } \\
\hline popmais60 & 1.539 .986 & 2,557 & 0,01 & 0,995 & -4.998 .123 & 5.028 .923 \\
\hline area & .0002819 &, 062 & $-0,00$ & 0,996 & -.1227007 & .122137 \\
\hline municipios & -.018804 & 1,213 & $-0,00$ & 1,000 & -2.378 .687 & 237.831 \\
\hline pib07 & -.0128171 & 1,695 & $-0,01$ & 0,994 & -3.335 .471 & 3.309 .837 \\
\hline gini91 & -2.670 .083 & . & . & . & . & . \\
\hline idh00 & -3.764 .232 & . & . & . & . & . \\
\hline agencias05 & -.1733486 & 1,471 & $-0,00$ & 0,999 & -2.885 .003 & 2.881 .536 \\
\hline emissivo & -2.778 .753 & 5,976 & $-0,01$ & 0,996 & -11741.95 & 11686.38 \\
\hline receptivo & 9.791 .409 & . & . & . & & . \\
\hline litoranea & -4.100 .201 & 9,797 & $-0,00$ & 0,997 & -19244.2 & 19162.19 \\
\hline pop2009 & -.0000166 &, 005 & $-0,00$ & 0,997 & -.0100665 & .0100333 \\
\hline cons & 1.928 .895 & . & . & . & . & . \\
\hline \multicolumn{7}{|c|}{ Método de pareamento $=$ nearest neighbor $=$ pscore } \\
\hline Variável amostra & & Tratado & Controle & Diferença & S.E & T-stat \\
\hline \multicolumn{7}{|l|}{ Hospedagem 08} \\
\hline ATT & & 176,75 & 555 & $-37,825$ & & \\
\hline
\end{tabular}

Fonte: Elaboração do autor

A Tabela 9 apresenta os resultados obtidos a partir da utilização da variável transformada (novaHospedagem08): 
Tabela 09 - Resultados da análise logística que estima os escore de propensão para pareamento com a variável modificada novaHospedagem 08

\begin{tabular}{|c|c|c|c|c|c|c|}
\hline \multicolumn{5}{|c|}{ Log da probabilidade $=-2.567 e-07$} & $\begin{array}{l}\text { No observ. = } \\
\text { LR qui2(11) } \\
= \\
\text { Prob > qui2 } \\
= \\
\text { Pseudo R2 } \\
=\end{array}$ & $\begin{array}{r}27 \\
32.82 \\
0.0010 \\
1.000\end{array}$ \\
\hline Participou & Coef. & $\begin{array}{c}\text { Erro- } \\
\text { padrão }\end{array}$ & z & $P>|z|$ & \multicolumn{2}{|c|}{ [95\% Intervalo conf] } \\
\hline popmais60 & 1.776 .484 & 2.437 .255 & 0,01 & 0,994 & -4.759 .167 & 4.794 .697 \\
\hline area & .0000169 & .0297828 & 0,00 & 1,000 & -.0583562 & .05839 \\
\hline municipios & .0469525 & 127.905 & 0,00 & 1,000 & -2.506 .423 & 2.507 .362 \\
\hline pib07 & -.0038883 & 2.247 .725 & 0,00 & 0,999 & -4.409 .349 & 4.401 .573 \\
\hline gini91 & -1.375 .259 & . & . & . & . & . \\
\hline idh00 & -1.207 .422 & . & . & . & . & . \\
\hline agencias05 & -.0623049 & 4.822 .801 & $-0,00$ & 0,999 & -9.458 .747 & 9.446 .286 \\
\hline emissivo & -2.951 .844 & 16215.94 & $-0,00$ & 0,999 & -31812.17 & 31753.13 \\
\hline receptivo & 8.215 .458 & 21063.77 & 0,00 & 0,997 & -41202.08 & 41366.39 \\
\hline litoranea & -187.378 & . & . & . & . & . \\
\hline pop2009 & -.0000251 & . & . & . & . & . \\
\hline novaHospe 08 & 4.659 .266 & . & . & . & . & . \\
\hline cons & 1.928 .895 & & . & . & . & . \\
\hline \multicolumn{7}{|c|}{ Método de pareamento $=$ nearest neighbor $=$ pscore } \\
\hline Variável amostra & & Tratado & Controle & Diferença & S.E & T-stat \\
\hline Hospedagem 08 & o-pareados & $\begin{array}{l}176,75 \\
17675\end{array}$ & $\begin{array}{c}123.736 .842 \\
657\end{array}$ & $\begin{array}{l}53.013 .157 \\
-48025\end{array}$ & 697.955 .548 & 0,76 \\
\hline
\end{tabular}

Fonte: Elaboração do autor

Após diversos testes, foi possível encontrar o modelo que utiliza a variável População com 60 anos ou mais. A Tabela 10 mostra os resultados obtidos e a Tabela 11 apresenta a porcentagem de redução do viés conseguida a partir do uso do propensity score. 
Tabela 10 - Resultados da análise logística que estima os escores de propensão para pareamento apenas com a variável poop60mais

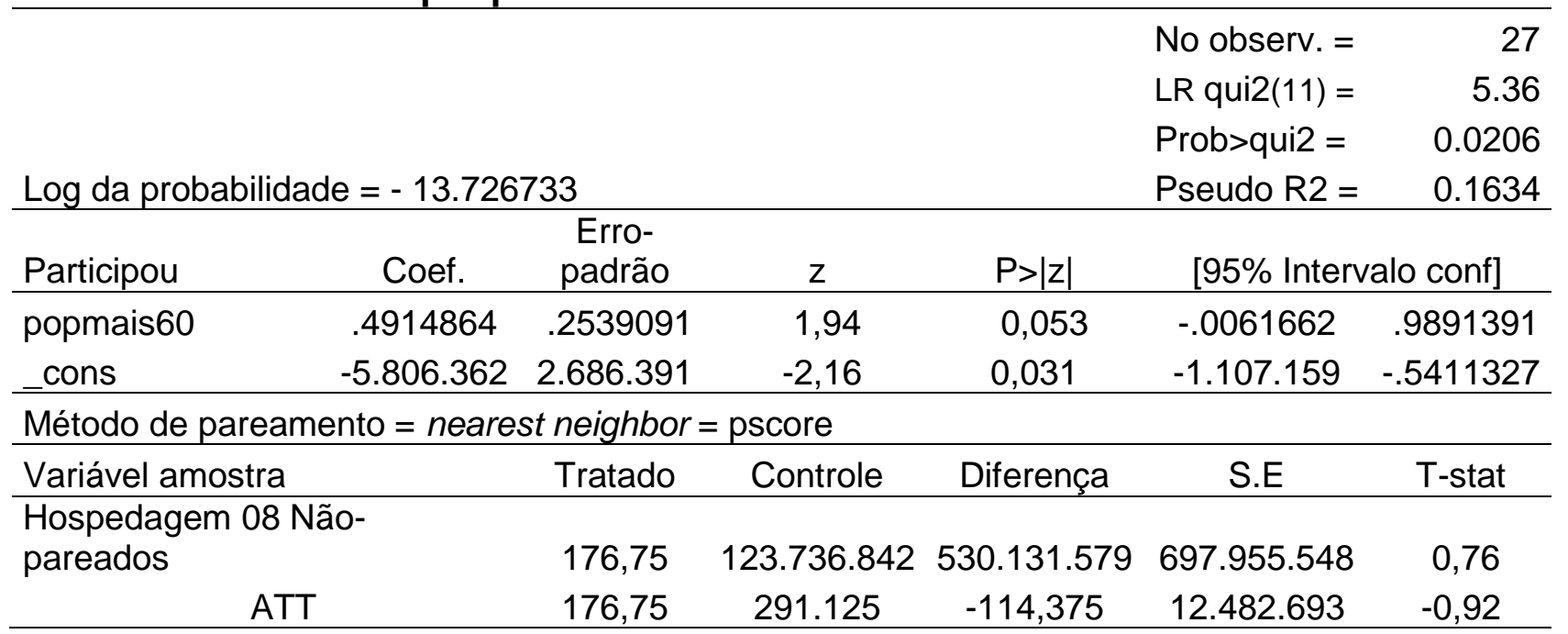

Tabela 11 - Redução do viés

\begin{tabular}{llcccccc}
\hline & & \multicolumn{2}{c}{ Média } & \multicolumn{3}{c}{ \%Redução } & \multicolumn{2}{c}{$\mathrm{t}$-test } \\
Variável & Amostra & Tratamento & Controle & $\%$ Viés & $\mid$ viés $\mid$ & $\mathrm{t}$ & $\mathrm{p}>|\mathrm{t}|$ \\
\hline Hospedagem08 & Não-pareados & 176,75 & 123,74 & 35,6 & & 0,76 & 0,455 \\
& Pareados & 176,75 & 175,63 & 0,8 & 97,9 & 0,02 & 0,984 \\
\hline
\end{tabular}

Fonte: Elaboração do autor

A partir desses resultados, pode-se verificar o valor de 0,053 para o nível crítico, ou seja, o modelo de classificação - propensity score - foi significativo. Esse resultado levou ao cálculo do ATT (Avarege Effect of the Treatment on the Treated) por meio do comando bootstrap r(att) do STATA. O ATT representa a diferença média entre o efeito da campanha no grupo de tratamento e no grupo de controle. Para este trabalho, é a diferença média da variável Hospedagem08 Média de grupo que foi alvo da campanha e do grupo que não foi contemplado.

Tabela 11 - Resultados da análise ATT

No de obs. $=\quad 27$

$\begin{array}{lll}\text { Bootstrap results } \quad \text { Replicações }= & 50\end{array}$

Comando: psmatch2 participou pop60mais, logit out( Hospedagem08) bs_1: (att)

\begin{tabular}{llcccc}
\hline Observado & $\begin{array}{l}\text { Bootstrap } \\
\text { Erro }\end{array}$ & & & & Normal-based \\
Coef. & padrão & $\mathrm{z}$ & $\mathrm{P}>|\mathrm{z}|$ & {$[95 \%$ Intervalo conf.] } \\
\hline- & & & & & \\
114.375 & 1.136 .858 & -1.01 & 0,314 & -337.195 & 108.445 \\
\hline Fonte: Elaboração do autor & & & &
\end{tabular}

Fonte: Elaboração do autor 
A partir do cálculo do $A T T$ foi possível verificar que a diferença entre o grupo de tratamento e o grupo de controle não foi significativa. $O$ valor de 0,314 observado ultrapassa a significância de 0,05 utilizada como referência nesse trabalho.

Os resultados obtidos permitem a construção do Gráfico 5 a seguir, que mostra a distribuição das observações. Quanto mais observações pareadas, melhor, ou seja, quanto mais UF's do grupo de controle forem pareadas com UF's do grupo de tratamento, melhor o resultado do modelo. O gráfico mostra, então, que para algumas observações não foi possível o pareamento, o que significa um resultado muito distante das demais em termos de propensão a ser alvo da campanha "Viaja Mais Maior Idade".

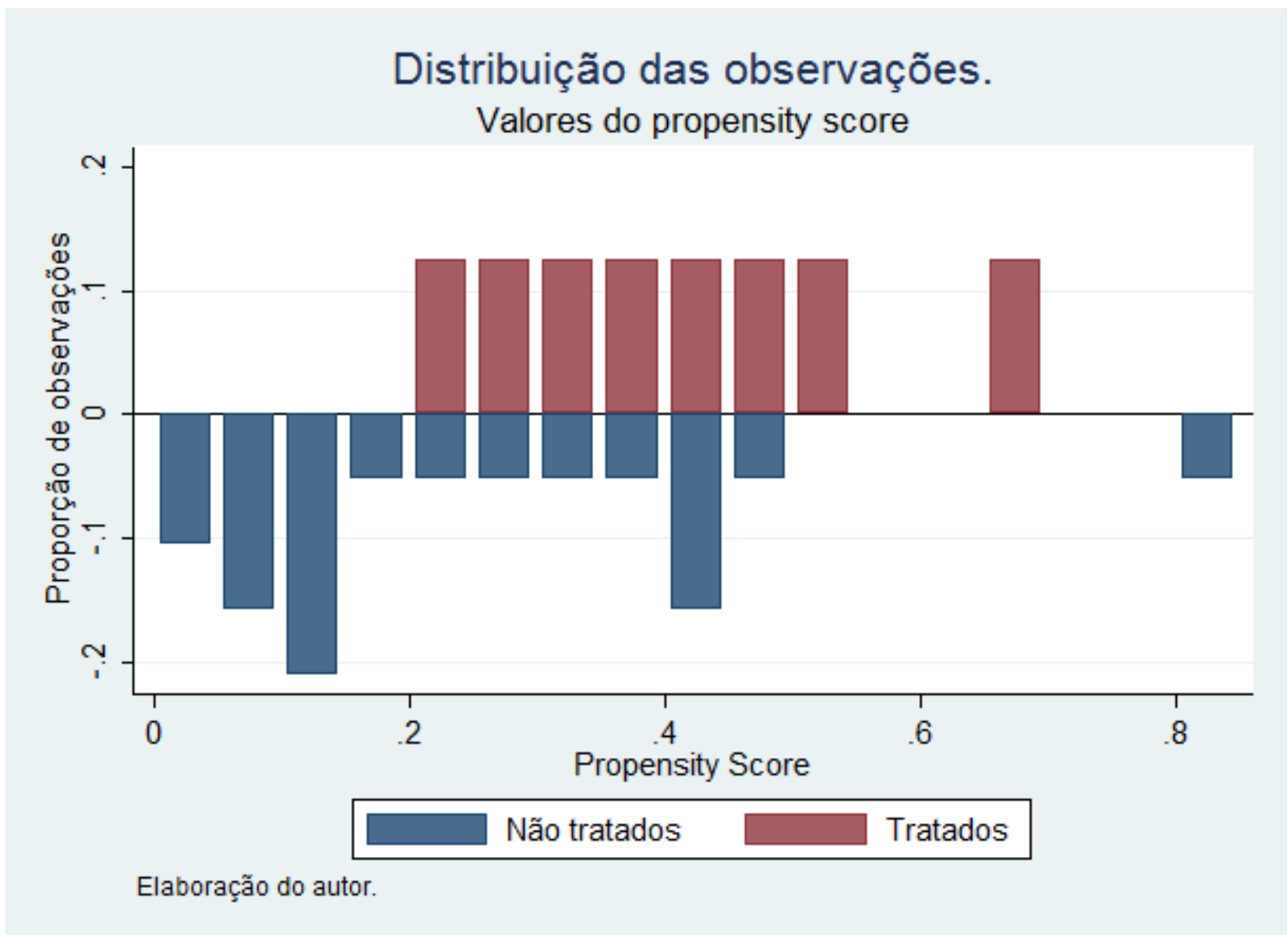

Gráfico 5: Distribuição das observações

Após a aplicação da técnica do PSM, chegou-se ao tamanho amostral de 8 UFs. Ou seja, dentre as 27 Unidades da Federação, 8 foram pareadas: Ceará, Paraíba, Alagoas, Bahia, São Paulo, Santa Catarina, Rio Grande do Sul e Goiás. 


\section{CONCLUSÕES E RECOMENDAÇÕES}

A avaliação de programas e políticas públicas tem se tornado assunto de grande relevância dentro da Administração Pública. As avaliações de políticas públicas realizadas atualmente ainda são superficiais e enviesadas. A campanha publicitária "Viaja Mais melhor Idade", elaborada pelo Ministério do Turismo com o objetivo de fomentar a atividade turística nos períodos de baixa temporada e promover a inclusão social da população com 60 anos ou mais é uma das vertentes da política pública desenvolvida para o turismo brasileiro.

A questão levantada é descobrir qual teria sido o efeito real dessa campanha em termos de meios de hospedagem cadastrados no MTur, para poder participar da campanha, é necessário que o meio de hospedagem esteja cadastrado no Ministério. Caso a campanha traga efeitos positivos, mais donos de meios de hospedagem terão interesse em ter seus empreendimentos cadastrados.

Dada a restrição imposta pelos dados, optou-se pelo método do propensity score, que busca diminuir o viés causado pela não randomização da amostra.

Os resultados obtidos apontam baixa significância em relação à diferença média entre a variável Hospedagem08 média do grupo de tratamento e do grupo de controle $(A T T)$. Esse resultado pode ter sido causado por duas situações:

1. A baixa quantidade de observações;

2. Realmente não há diferença significante entre o grupo de tratamento e o de controle em relação aos efeitos da campanha.

A pequena quantidade de observações é explicada pela baixa coleta de dados por parte do Governo Federal, em específico o Ministério do Turismo. Por causa de dificuldades orçamentárias, ao órgão fica a tarefa de escolher entre fazer campanhas ou fazer pesquisas, que demandam muitos recursos. Ainda não há, de fato, a preocupação efetiva com a coleta de informações antes e após as campanhas, de modo que seja possível elaborar avaliações mais completas em relação aos efeitos reais das campanhas propostas pelo órgão. Quando a coleta é feita, priorizam-se dados referentes aos turistas internacionais e, quase nunca, esses dados são separados por Unidades da Federação, formato adotado para esse trabalho. A essa restrição de dados justifica-se a adoção da hospedagem como 
variável de comparação, dado ter sido essa a única informação referente ao setor com períodos anteriores e posteriores à campanha e separados por UF.

Exposta a situação, a primeira recomendação seria a de criação de uma rotina de mensuração de dados antes e após cada campanha elaborada pelo órgão. Sem essas informações se torna praticamente inviável a elaboração de qualquer tipo de avaliação (RAMOS, 2009).

Caso seja verdadeira a hipótese de que realmente não existe diferença significativa entre grupo de tratamento e de controle em termos de meios de hospedagem cadastrados, infere-se a ineficiência da campanha elaborada pelo Ministério e a falta de resultados mensuráveis na utilização dos recursos públicos.

Adotando como verdadeira essa hipótese, recomendaria-se então que esse tipo de avaliação fosse realizada para cada campanha elaborada pelo órgão. $A$ descoberta de quais campanhas estão sendo eficientes permite que essas sejam utilizadas como modelo para o desenvolvimento de novas campanhas também eficientes no aumento da atividade turística, o que direcionaria os recursos às ações que de fato conseguem trazer o resultado esperado.

Além da descoberta de quais campanhas são eficientes, descobriria-se também aquelas que não foram capazes de trazer o resultado esperado, permitindo uma análise mais objetiva e profunda em relação aos motivos que possam ter sido causa do insucesso e um melhor aproveitamento dos recursos direcionados às campanhas. A campanha objeto desse estudo, por exemplo, vem sendo relançada desde 2007. Considerada verdadeira a hipótese de que a mesma não está sendo capaz de trazer resultados mensuráveis para o turismo brasileiro, conclui-se há 3 anos recursos públicos vêm sendo utilizados de forma ineficiente.

Essa conclusão e a adoção de medidas para reparar os possíveis erros só são possíveis porque uma avaliação foi realizada. Assim como essa campanha, muitas outras podem estar sendo consideradas sucesso pelo Brasil não porque são, de fato, eficientes em cumprir com seus objetivos, mas porque não são avaliadas ou as avaliações realizadas são superficiais. Essas campanhas, normalmente, possuem um apelo emocional grande, com músicas e imagens atraentes. $O$ resultado em termos de visibilidade ou de popularidade da campanha não significa que o turista em potencial tenha se tornado um turista de fato. Por isso é tão relevante que as avaliações desse tipo de campanha sejam rotina para o Ministério do Turismo. 
Talvez seja uma possibilidade, então, repensar o uso dos recursos em termos de campanhas publicitárias. Pode-se, por exemplo, criar programas de subsídios de viagens, o que levaria o turista a movimentar a economia do destino. Assim como a campanha "Viaja Mais Melhor Idade", um programa dessa natureza poderia também ter uma função social, dependendo do tipo de subsídio.

É possível concluir, assim, que o processo de avaliação é fundamental para que as atividades planejadas pelo Governo em termos de publicidade para o aumento da atividade turística sejam eficazes em seus propósitos. Vale ressaltar que atualmente são realizadas avaliações, mas conforme exposto ao longo deste trabalho, essas avaliações ainda são realizadas de forma superficial e amadora, não sendo capazes de corresponder à magnetude e importância das políticas e, mais especificamente, das camapnhas publicitárias elaboradas pelo órgão.

Uma vez detectada essa relevância de avaliar, evidencia-se a carência de recursos - dados - para que o Ministério do Turismo possa dar passos inteligentes em direção ao crescimento da atividade turística brasileira, que, conforme exposto, ainda precisa ser muito bem trabalhada para tornar-se competitiva em relação ao turismo mundial. 


\section{REFERÊNCIAS}

ALBUQUERQUE, S. F. Princípios Orientadores para Divulgação de Material Promocional de Destino Tursístico dentro do Marco da Comunicação para Sustentabilidade. Brasília, CET/UnB: 2009.

BARRETTO, M. Planejamento e organização em turismo. $9^{a}$ ed. Campinas, Papirus, 2003.

BRASIL. Ministério do Turismo. Estudo da Competitividade do Turismo Brasileiro - Economia do Turismo. Brasília, MTur, 2006.

BRASIL. Ministério do Turismo. O Turismo no Brasil: Panorama Geral, Avaliação da Competitividade e Propostas de Políticas Públicas. Brasília, MTur, 2006.

BRASIL. Ministério do Turismo. Plano Cores do Brasil. Brasília, MTur, 2005.

BRASIL. Ministério do Turismo. Plano Nacional de Turismo - Diretrizes, Metas e Programas 2003-2007. Brasília, MTur, 2003

BRASIL. Ministério Turismo. Plano Nacional de Turismo 2007-2010: uma viagem de inclusão. Brasília, MTur, 2007.

BRASIL. Relatório de Avaliação. Plano Plurianual 2008-2011. Brasília, MTur, 2009.

BRASIL. Ministério do Turismo. Relatório Executivo do Turismo Doméstico. Brasília, MTur, 2009.

CASTELLI, G. Turismo e Marketing. Livraria Sulina Editora. Porto Alegre, 1984.

CHIAVENATO, I. Introdução à Teoria Geral da Administração. 3. Ed. Atlas, São paulo, 2004.

COBRA, M. Marketing de Turismo. Cobra Editora \& Marketing. São Paulo, 2001.

COBRA, M. Administração de Marketing no Brasil. 2. Ed. Cobra Editora \& Marketing. São Paulo, 2005. Disponível em:

http://books.google.com.br/books?hl=pt- 
$B R \& \mid r=\& i d=z A x 2 K n w c E S o C \& o i=f n d \& p g=P A 14 \& d q=O+q u e+\% C 3 \% A 9+$ marketing $+r i c$ hers\&ots $=t F 7 X s Q d u z e \& s i g=U p w V c P t D 7 p t B f n D B J e C d U a U 5 Q Y o \# v=0$ nepage $\& q=0 \%$ 20 que\%20\%C3\%A9\%20marketing\%20richers\&f=false. Acesso em: 20 jun. 2010.

COZBY, Paulo C. Métodos de Pesquisa em Ciências do Comportamento. 1. Ed. 2003 - 4. reimpr. - São Paulo, Atlas, 2009.

FARIA, C. A. P. A Política da Avaliação de Políticas Públicas. Revista Brasileira de Ciências Sociais. V. 20. N. 59 São Paulo, 2005. Disponível em:

http://www.scielo.br/pdf/\%0D/rbcsoc/v20n59/a07v2059.pdf

FUNDAÇÃO INSTITUTO DE PESQUISAS ECONÔMICAS - FIPE. Tendências Macro do Turismo Mundial. Brasília, FIPE, 2006.

FUNDAÇÃO INSTITUTO DE PESQUISAS ECONÔMICAS - FIPE. Caracterização e Dimensionamento do Turismo Doméstico no Brasil. São Paulo, FIPE, 2006.

GIL, Antônio Carlos. Métodos e Técnicas de Pesquisa Social. São Paulo, Altas, 1994.

KOTLER, P.; KELLER, K. L. Administração de Marketing. 12. Ed. São Paulo, Pearson Prentice Hall, 2006.

KRIPPENDORF, Jost. Sociologia do turismo: para uma nova compreensão do lazer e das viagens. 3. Ed. São Paulo, Aleph, 2003.

LAKATOS, E. M.; MARCONI, M. A. Metodologia Científica. 3. Ed. São Paulo, Atlas, 2000.

MELGAR, Ernesto. Fundamentos de planejamento e marketing em turismo. São Paulo, Contexto, 2001.

MINISTÉRIO DO TURISMO. Viaja Mais Melhor Idade. Disponível em: http://www.viajamais.com.br/viajamais/. Acesso em: 27 jun. 2010.

MOESCH, Marutschka. A Produção do Saber Turístico. São Paulo, Contexto, 2002.

MOTA, Keila Cristina Nicolau. Marketing turístico: promovendo uma atividade sazonal. São Paulo, Atlas, 2001. 
NSSAH, B. E. Propensity Score Matching and Policy Impact Analysis.

Washington, D.C., The World Bank, 2006.

PORTAL DA TRANSPARÊNCIA. Gastos Diretos do Governo. Disponível em: http://www.portaldatransparencia.gov.br/PortalComprasDiretasOEOrgaoSubordinado .asp? Ano $=2008 \&$ Valor $=93112214467370 \&$ CodigoOS $=54000 \&$ NomeOS=MINISTERI M\%20DO\%20TURISMO\&ValorOS=23787997856. Acesso em: 30 jul. 2010.

RAMOS, M. Aspectos Conceituais e Metodológicos da Avaliação de Políticas e Programas Sociais. Brasília, IPEA, 2009.

RICHARDSON, R. J. Pesquisa social: métodos e técnicas. 3. ed. São Paulo, Altlas, 1999.

RICHERS, R. O que é Marketing. São Paulo, Brasiliense, 1986.

ROSENBAUM, P; RUBIN, D. The Central Role of the Propensity Score in Observational Studies for Causal Effects. Biometrika, Vol. 70, N. 1:41-55, 1983.

RUSCHMANN, D. M. Marketing Turístico: Um Enfoque Promocional. $2^{\underline{a}}$ Edição. Ed. Campinas, 1995.

SAMPAIO, C. H.; PERIN, M. G. Pesquisa científica da área de marketing: uma revisão histórica. Rev. adm. contemp., Curitiba, Vol. 10, N. 2, Jun. 2006.

Disponível em http://www.scielo.br/scielo.php?script=sci_arttext\&pid=S141565552006000200010\&lng=en\&nrm=iso >. Acesso em: 22 jun. 2010.

SAKATA. M. C .G., Tendências Metodológicas da Pesquisa Acadêmica em Turismo. São Paulo, ECA/USP, 2002.

SANTANA, G. Adequação e Eficácia de Programas de Marketing Turístico de Balneário Camburiú, Santa Catarina. Salvador, EnANPAD, 2006.

SELLTIZ; WRIGHTSMAN; COOK. Métodos de Pesquisa nas Relações Sociais. São Paulo, EPU, 1987.

SIANESI, B. Implementing Propensity Score Matching Estimators with STATA. Londres, 2001.

TAVARES, Priscila Albuquerque. Efeito do Programa Bolsa Família sobre a Oferta de Trabalho das Mães. Minas Gerais, UFMG, 2008. 
TEIXEIRA, C. P.; RIBEIRO, T. A Produção do Conhecimento Científico no Turismo. Revista de Turismo - PUC Minas, Vol. 1, N. 1, Nov. 2005.

TOMIKAWA, J. M., Marketing turístico e internet: uma análise dos sites oficiais de turismo dos estados brasileiros. Brasília, CET/UnB, 2009.

VERGARA, S. C. Projetos e Relatórios de Pesquisa em Administração. S.I.: Atlas, 1998.

WONG, K.; SONG, H. Tourism Forecasting adn Marketing. THHP, Vol. 13, N. 1/2, 2002. 


\section{ANEXOS}

\section{Anexo A - Imagens da campanha "Viaja Mais Melhor Idade" para o lançamento de 2010}
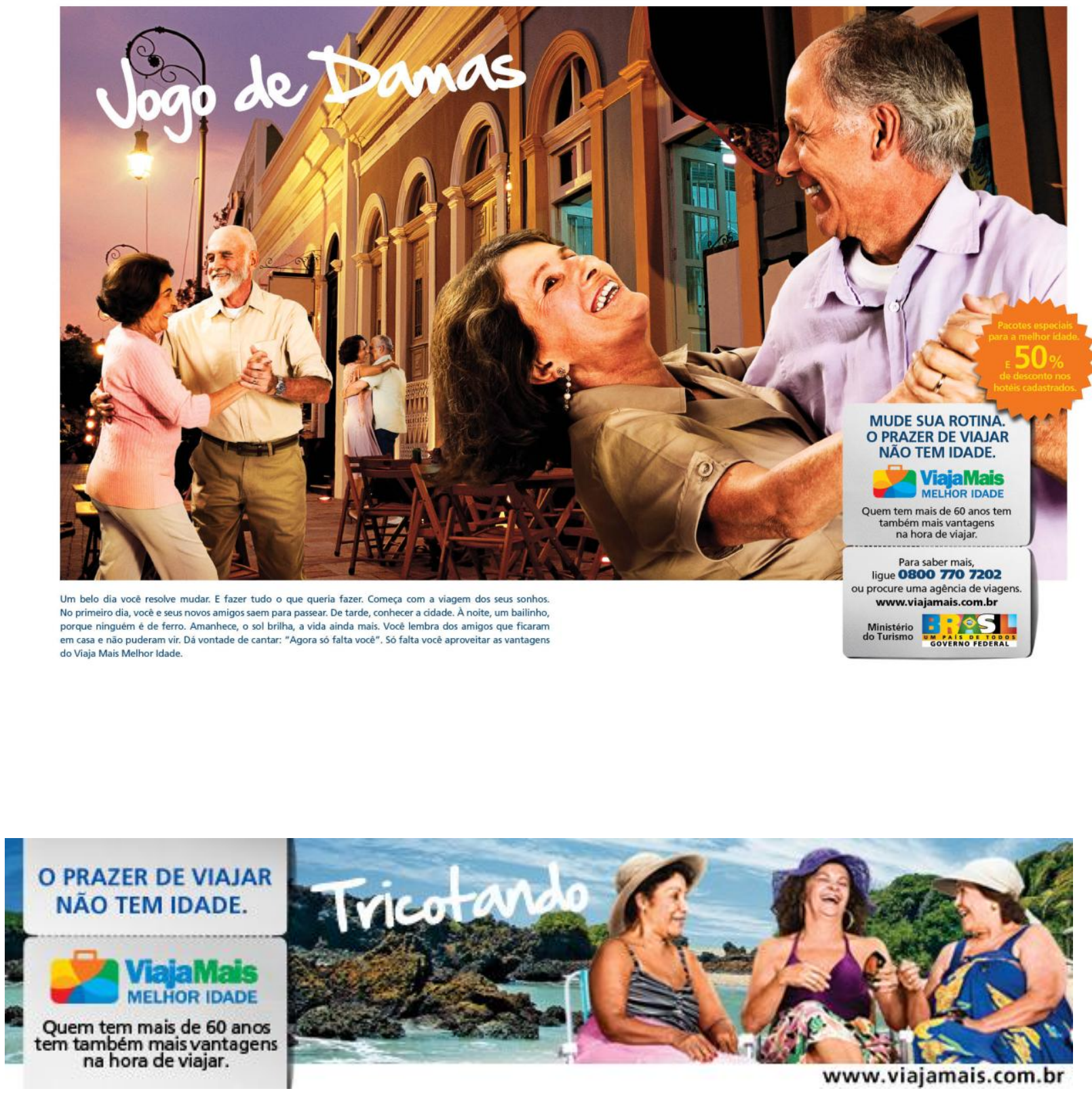


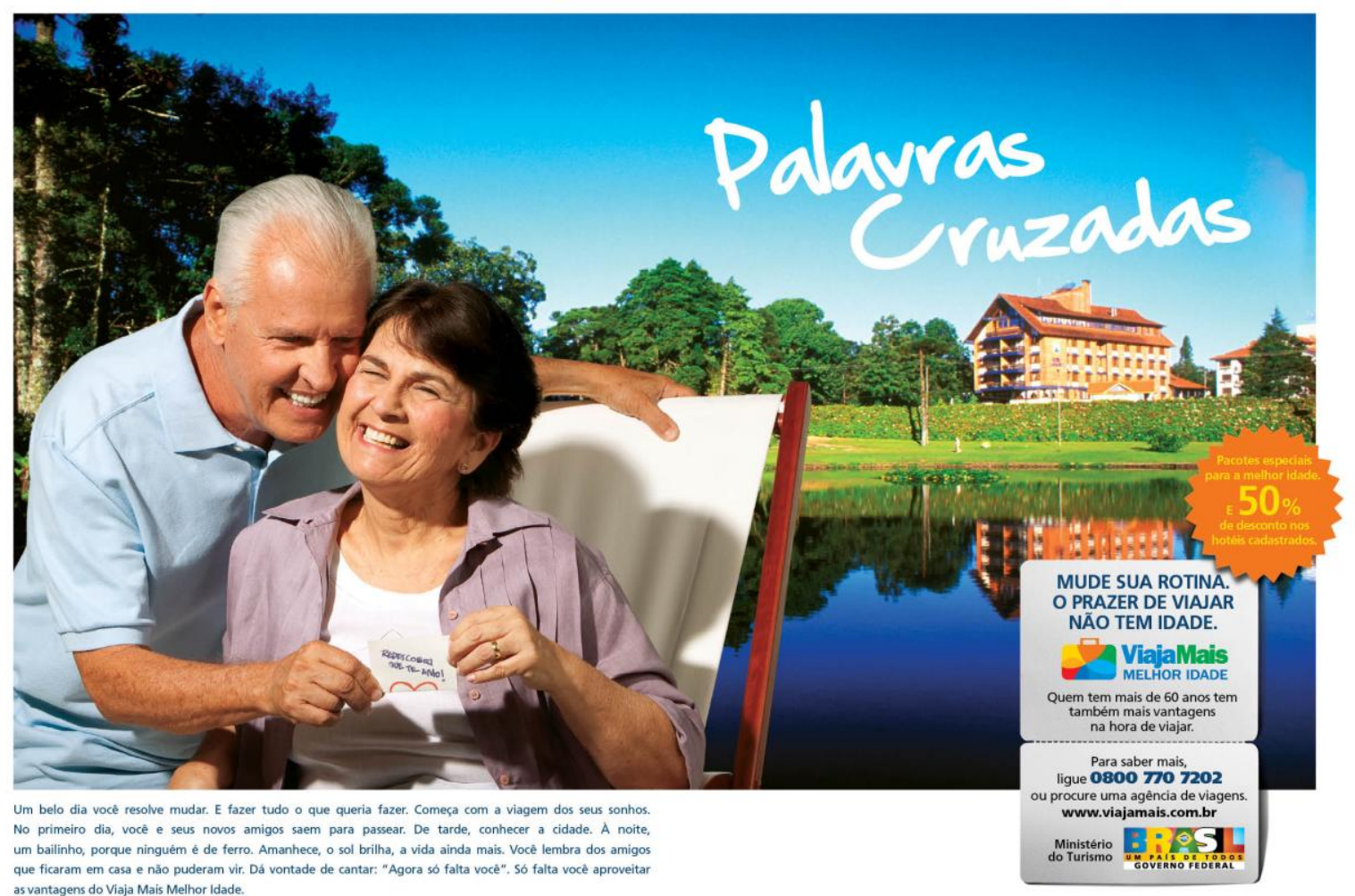




\section{APÊNDICES}

\section{Apêndice A - Variáveis independentes por Unidade da Federação}

(continua)

PIB Per capita $(2007)^{*} \quad$ Índice de Gini 1991* $\quad$ IDH

\begin{tabular}{lccc}
\hline Rondônia & $10.319,98$ & 0,600 & 0.735 \\
Acre & $8.789,49$ & 0,610 & 0.697 \\
Amazonas & $13.042,83$ & 0,621 & 0.713 \\
Roraima & $10.534,08$ & 0,617 & 0.746 \\
Pará & $7.006,81$ & 0,602 & 0.723 \\
Amapá & $10.253,74$ & 0,568 & 0.753 \\
Tocantins & $8.920,73$ & 0,628 & 0.71 \\
Maranhão & $5.165,23$ & 0,601 & 0.636 \\
Piauí & $4.661,56$ & 0,630 & 0.656 \\
Ceará & $6.149,03$ & 0,647 & 0.7 \\
Rio Grande do Norte & $7.607,01$ & 0,646 & 0.705 \\
Paraíba & $6.097,04$ & 0,638 & 0.661 \\
Pernambuco & $7.336,78$ & 0,660 & 0.705 \\
Alagoas & $5.858,37$ & 0,632 & 0.649 \\
Sergipe & $8.711,70$ & 0,632 & 0.682 \\
Bahia & $7.787,40$ & 0,653 & 0.688 \\
Minas Gerais & $12.519,40$ & 0,635 & 0.773 \\
Espírito Santo & $18.002,92$ & 0,612 & 0.765 \\
Rio de Janeiro & $19.245,08$ & 0,624 & 0.807 \\
São Paulo & $22.667,25$ & 0,580 & 0.82 \\
Paraná & $15.711,20$ & 0,610 & 0.787 \\
Santa Catarina & $17.834,00$ & 0,565 & 0.822 \\
Rio Grande do Sul & $16.688,74$ & 0,598 & 0.814 \\
Mato Grosso do Sul & $12.411,18$ & 0,614 & 0.778 \\
Mato Grosso & $14.953,58$ & 0,601 & 0.773 \\
Goiás & $11.547,68$ & 0,620 & 0.776 \\
Distrito Federal & $40.696,08$ & 0,609 & 0.844 \\
\hline Fonte: *IBGE** PNUD & & &
\end{tabular}

Fonte: *IBGE ** PNUD 
(continuação)

\begin{tabular}{|c|c|c|c|c|c|c|}
\hline & \multicolumn{3}{|c|}{$\begin{array}{l}\text { Agências de turismo } \\
\text { cadastradas no Mtur*** }\end{array}$} & \multicolumn{3}{|c|}{$\begin{array}{c}\text { Participação relativa entre UF's }{ }^{* \star * \star} \\
\text { Emissivas e Receptivas }\end{array}$} \\
\hline & 2003 & 2004 & 2005 & $\begin{array}{c}(\%) \\
\text { Emissivo } \\
1\end{array}$ & $\begin{array}{c}(\%) \\
\text { Receptivo } \\
2\end{array}$ & $\begin{array}{c}\text { Relação } \\
(1 / 2)\end{array}$ \\
\hline Rondônia & 34 & 36 & 39 & 0,3 & 0,3 & 1 \\
\hline Acre & 15 & 18 & 18 & 0,1 & 0,1 & 1 \\
\hline Amazonas & 99 & 115 & 136 & 0,5 & 0,5 & 1 \\
\hline Roraima & 20 & 18 & 18 & 0,1 & 0,1 & 1 \\
\hline Pará & 114 & 132 & 137 & 1,4 & 1,2 & 1,2 \\
\hline Amapá & 24 & 37 & 43 & 0,1 & 0,1 & 1 \\
\hline Tocantins & 20 & 24 & 24 & 0,3 & 0,4 & 8 \\
\hline Maranhão & 80 & 97 & 101 & 0,7 & 1 & 0,7 \\
\hline Piauí & 51 & 54 & 63 & 0,6 & 0,7 & 0,9 \\
\hline Ceará & 186 & 206 & 225 & 3 & 3,5 & 0,9 \\
\hline Rio Grande do Norte & 104 & 89 & 108 & 0,7 & 1,3 & 0,5 \\
\hline Paraíba & 92 & 91 & 83 & 1,3 & 1,2 & 1,1 \\
\hline Pernambuco & 160 & 194 & 217 & 2,7 & 2,9 & 0,9 \\
\hline Alagoas & 106 & 108 & 126 & 0,9 & 1 & 0,9 \\
\hline Sergipe & 49 & 67 & 74 & 0,9 & 1,1 & 0,8 \\
\hline Bahia & 318 & 440 & 452 & 5,9 & 7,4 & 0,8 \\
\hline Minas Gerais & 686 & 709 & 733 & 16,4 & 11,4 & 1,4 \\
\hline Espírito Santo & 112 & 129 & 164 & 1,6 & 1,9 & 0,8 \\
\hline Rio de Janeiro & 1178 & 1166 & 1253 & 7,4 & 8 & 0,9 \\
\hline São Paulo & 1790 & 1841 & 2073 & 30,4 & 27,3 & 1,1 \\
\hline Paraná & 810 & 833 & 889 & 6,3 & 5,8 & 1,1 \\
\hline Santa Catarina & 450 & 484 & 473 & 4,3 & 6,5 & 0,7 \\
\hline Rio Grande do Sul & 743 & 763 & 855 & 8,9 & 7,2 & 1,2 \\
\hline Mato Grosso do Sul & 173 & 183 & 189 & 0,9 & 1,5 & 0,6 \\
\hline Mato Grosso & 104 & 126 & 129 & 1 & 1,1 & 0,9 \\
\hline Goiás & 160 & 156 & 181 & 2,3 & 3,3 & 0,7 \\
\hline Distrito Federal & 246 & 305 & 327 & 1,4 & 3,3 & 0,4 \\
\hline
\end{tabular}


(continuação)

\begin{tabular}{|c|c|c|c|c|c|}
\hline & \multirow{2}{*}{ Litorânea } & \multicolumn{3}{|c|}{$\begin{array}{c}\text { Meios de hospedagem }{ }^{* * *} \\
\text { cadastrados } \\
\text { No Mtur }\end{array}$} & \multirow{2}{*}{ Participou? } \\
\hline & & 2006 & 2007 & 2008 & \\
\hline Rondônia & Não & 3 & 60 & 89 & 0 \\
\hline Acre & Não & 0 & 1 & 1 & 0 \\
\hline Amazonas & Não & 13 & 43 & 84 & 0 \\
\hline Roraima & Não & 2 & 3 & 8 & 0 \\
\hline Pará & Sim & 20 & 24 & 33 & 0 \\
\hline Amapá & Sim & 5 & 7 & 10 & 0 \\
\hline Tocantins & Não & 6 & 15 & 34 & 0 \\
\hline Maranhão & Sim & 14 & 25 & 41 & 0 \\
\hline Piauí & Sim & 6 & 7 & 17 & 0 \\
\hline Ceará & Sim & 76 & 124 & 180 & 1 \\
\hline Rio Grande do Norte & Sim & 24 & 37 & 65 & 0 \\
\hline Paraíba & Sim & 9 & 23 & 47 & 1 \\
\hline Pernambuco & Sim & 32 & 55 & 98 & 0 \\
\hline Alagoas & Sim & 18 & 42 & 61 & 1 \\
\hline Sergipe & Sim & 6 & 10 & 16 & 0 \\
\hline Bahia & Sim & 94 & 174 & 299 & 1 \\
\hline Minas Gerais & Não & 179 & 379 & 555 & 0 \\
\hline Espírito Santo & Sim & 21 & 55 & 83 & 0 \\
\hline Rio de Janeiro & Sim & 266 & 358 & 657 & 0 \\
\hline São Paulo & Sim & 159 & 239 & 294 & 1 \\
\hline Paraná & Sim & 135 & 247 & 315 & 0 \\
\hline Santa Catarina & Sim & 37 & 65 & 113 & 1 \\
\hline Rio Grande do Sul & Sim & 161 & 236 & 263 & 1 \\
\hline Mato Grosso do Sul & Não & 79 & 107 & 127 & 0 \\
\hline Mato Grosso & Não & 16 & 40 & 100 & 0 \\
\hline Goiás & Não & 111 & 141 & 157 & 1 \\
\hline Distrito Federal & Não & 6 & 16 & 18 & 0 \\
\hline
\end{tabular}

Fonte:*** Estatísticas Básicas do Turismo 2009 